\title{
Dopaminergic Modulation of Dye Coupling between Neurons in the Core and Shell Regions of the Nucleus Accumbens
}

\author{
Patricio O'Donnell and Anthony A. Grace \\ Departments of Behavioral Neuroscience and Psychiatry, Center for Neuroscience, University of Pittsburgh, Pittsburgh, \\ Pennsylvania 15260
}

\begin{abstract}
The presence of dye coupling and electrotonic coupling within the nucleus accumbens was examined using intracellular recording and staining in rat brain slices. In $24 \%$ of the cells examined, injection of single accumbens neurons with the dye Lucifer yellow resulted in the complete labeling of more than one cell. To examine whether this coupling is regulated by dopamine (DA), the extent of dye coupling was assessed in the presence of dopaminergic agonists and antagonists. In the core region of the accumbens, $D_{1}$ receptor stimulation induced a decrease in the incidence of dye coupling; this effect could be blocked by the $D_{1}$ antagonists SCH 23390 and $\mathrm{SCH} 39166$, by the $D_{2}$ antagonist sulpiride, or by depletion of DA by reserpine and $\alpha$-methyl-p-tyrosine coadministration, but not by the atypical antipsychotic drug clozapine. In contrast, in the posterior part of the shell region, $D_{2}$ receptor stimulation increased the incidence of coupling independent of the state of $D_{1}$ receptor activation. Fast spikelets resembling coupling potentials were found to occur only in neurons that also showed dye coupling, and could be attenuated in core neurons by $D_{1}$ receptor stimulation. These findings suggest that DA, in addition to its actions on the membrane of single neurons, may also affect neuronal integration on a network level by regulating the transfer of information between adjacent neurons within the nucleus accumbens.
\end{abstract}

[Key words: dye coupling, Lucifer yellow, accumbens, basalganglia, dopamine, $D_{1}$ receptors, $D_{2}$ receptors, intracellular recording, electrical coupling, schizophrenia, clozapine]

Until relatively recently, communication between neurons in the vertebrate CNS was thought to occur exclusively by chemical synapses, with electrotonic transmission relegated to simpler invertebrate neural networks (Furshpan and Potter, 1959) or developing systems (Bennett et al., 1981). However, there was also anatomical and physiological evidence of its presence in lower vertebrates (Bennett, 1963; Yamada and Ishikawa, 1965; Kaneko, 1971), and in 1971 Baker and Llinás demonstrated

Received Dec. 4, 1992; revised Feb. 16, 1993; accepted Feb. 22, 1993.

We thank Dr. Andras Törb̌csik for his valuable suggestions, and for performing the HPLC assessments of dopamine levels, as well as Dr. Gloria Meredith for her suggestion of the comparison between the anterior and posterior parts of the shell, and $\mathrm{Mr}$. Mark Antkowiak, for his excellent technical assistance. The $\mathrm{D}_{1}$ antagonist SCH 39166 was kindly provided by Dr. Allen Rarnett (Schering-Plough, Bloomfield, NJ). This work was supported by MH 45156, MH 42217, NS 19608, and the Scottish Rite Schizophrenia Research Program.

Correspondence should be addressed to Dr. Patricio O'Donnell, Department of Behavioral Neuroscience, University of Pittsburgh, Pittsburgh, PA 15260

Copyright (C) 1993 Society for Neuroscience $0270-6474 / 93 / 133456-16 \$ 05.00 / 0$ that electrical transmission takes place between rat mesencephalic neurons (Baker and Llinás, 1971). Following this first report in the mammalian brain, physiological evidence for electrical coupling was found in several brain regions, including the inferior olive (Llinás et al., 1974), retina (Piccolino et al., 1982, 1984; Lasater and Dowling, 1985a,b), substantia nigra (Grace and Bunney, 1983), hippocampus (MacVicar and Dudek, 1981; Taylor and Dudek, 1982; Dudek and Snow, 1985; Núñez et al., 1990), striatum (Walsh et al., 1989), spinal cord motoneurons (Gogan et al., 1977; Walton and Navarrete, 1991), and lateral vestibular nucleus (Wylie, 1973). Electrotonic transmission is a mode of communication between sets of two or more cells in which apposed membranes are connected by gap junctions. These are transmembrane proteins (connexins) arranged so as to form a pore that allows direct electrical transmission and diffusion of small molecules, possibly including second messengers, between adjacent cells (Schmitt et al., 1976; Sotelo and Korn, 1978).

There is increasing evidence that electrotonic transmission is not passive in nature, but can be dynamically modulated by such factors as intracellular calcium levels and $\mathrm{pH}$ (Rose and Loewenstein, 1975; Ramón et al., 1985; Spray et al., 1985; Rao et al., 1987; Church and Baimbridge, 1991). Recent studies have focused on neurotransmitter-mediated modulation of gap junction conductance. In particular, studies of retina physiology have provided a functional model of this regulation, in which dopamine (DA), acting on $D_{1}$ receptors (Piccolino et al., 1984), may be involved in dark-adaptation mechanisms by suppressing electrotonic transmission between adjacent horizontal cells (Teranishi et al., 1983; Lasater and Dowling, 1985a,b; McMahon et al., 1989). Another system in which dopaminergic modulation of electrical transmission has been reported is the striatum, where the incidence of dye coupling can be increased by systemic administration of apomorphine in vivo (Onn et al., 1991 ) or by DA-depleting lesions made prior to in vitro recordings (Cepeda et al., 1989).

Due to the technical difficulty involved in performing simultaneous intracellular recordings from two coupled neurons to verify the existence of electrical communication between them, studies of vertebrate systems have relied on anatomical means to identify coupling between cells. Intracellular injection of gap junction-permeable dyes has become an accepted means of verifying cell coupling at a histological level, with the most commonly used dye for this purpose being Lucifer yellow. This dye has the ability to fill a cell completely after intracellular injection and is sufficiently compact to pass through gap junctions, causing cells that are coupled to the injected neuron to be labeled (Stewart, 1978, 1981). Thus, dye coupling has proven to be a 
rcliable indicator of electrotonic coupling between neurons in a number of brain regions (Andrew et al., 1981; Gutnick and Prince, 1981; Grace and Bunney, 1983; Dudek and Snow, 1985; Walsh et al., 1989; Núñez et al., 1990). In fact, the correlation between gap junctions, dye coupling, and electrical coupling has recently been substantiated in an elegant series of studies in which cells that normally do not express gap junction proteins were transfected with connexin 32-encoding cDNA, resulting in the induction of both dye and electrical coupling (Eghbali et al., 1990, 1991a,b; Moreno et al., 1991).

In this study we examined whether coupling was present between cells in the limbic counterpart of the striatum, known as the nucleus accumbens, which is known to receive a dense DA innervation (Chronister et al., 1981; Oades and Halliday, 1987; Deutch and Cameron, 1992; Parsons and Justice, 1992). The nucleus accumbens has been gaining attention as evidence of its involvement in several psychiatric disorders, including schizophrenia (Matthysse, 1973, 1981; Snyder, 1973; Stevens, 1973) and Tourette's syndrome (Comings, 1987), as well as in the therapeutic actions of antipsychotic drugs (APDs; White and Wang, 1983), has come to light. This nucleus is composed of two subdivisions (Záborszky et al., 1985; Paxinos and Watson, 1986; Zahm and Heimer, 1988): (1) the core, which is proposed to be a functional extension of the ventral striatum, and (2) a ventromedial shell, which several investigators suggest may be part of a continuum of cells extending from the amygdala through the bed nucleus of the stria terminalis, and known collectively as the extended amygdala (Alheid and Heimer, 1988; Heimer et al., 1991). Although these two regions are known to differ in their connectivity patterns (Záborszky et al., 1985; Meredith et al., 1989; Zahm and Heimer, 1990; Heimer et al., 1991; Berendse et al., 1992a) and in their neurochemistry (Zahm and Heimer, 1988; Meredith et al., 1989; Zahm, 1992), electrophysiological evidence shows that neurons located in the core and shell regions of the accumbens exhibit similar intrinsic membrane properties (O'Donnell and Grace, 1993a). The presence of coupling was assessed by performing intracellular recording and Lucifer yellow staining of neurons in several regions of the rat nucleus accumbens maintained in vitro.

Some of these data have been presented in abstract form (O’Donnell and Grace, 1991a).

\section{Materials and Methods}

Preparation of slices. Intracellular recordings and staining of accumbens neurons were performed in rat brain slices containing both core and shell regions. Male adult Sprague-Dawley rats, obtained from ZivicMiller laboratories (Allison Park, PA) and wcighing 180-280 gm, were used in this study. All experiments were performed in accordance with the Guide for the Care and Use of Laboratory Animals published by the U.S. Public Health Service, with the protocols approved by the University of Pittsburgh Institutional Animal Care and Use Committee. Animal handling and electrophysiological recordings were performed as described previously (Grace and Onn, 1989). Briefly, rats were deeply anesthetized with chloral hydrate $(400 \mathrm{mg} / \mathrm{kg}$, i.p.) prior to decapitation. Brains were quickly removed and $4 \mathrm{~mm}$ parasagittal blocks containing both accumbens nuclei were made using Activational Systems Rat Brain Matrices (RBM-4000S). The tissue was then sectioned in ice-cold physiological saline solution ( $124 \mathrm{mM} \mathrm{NaCl}, 5 \mathrm{~mm} \mathrm{KCl}, 1.2 \mathrm{~mm} \mathrm{KH}_{2} \mathrm{PO}_{4}$, $2.4 \mathrm{~mm} \mathrm{CaCl}_{2}, 1.3 \mathrm{~mm} \mathrm{MgSO}_{4}, 26 \mathrm{mM} \mathrm{NaHCO}_{3}, 10 \mathrm{~mm}$ glucose, and saturated with $95 \%: 5 \% \quad \mathrm{O}_{2}: \mathrm{CO}_{2}$ ) into $400-\mu \mathrm{m}$-thick slices using a Vibratome (Oxford, UK). Sections were incubatcd for at lcast $1 \mathrm{hr}$ at room temperature in continuously oxygenated physiological saline before placing them into a submersion-type recording chamber that was superfused with oxygenated physiological saline delivered at a flow rate of 1-2 $\mathrm{ml} / \mathrm{min}$ using a peristaltic pump (Haake-Büchler MCP 2500)
(Llinás and Sugimori, 1980; Grace and Llinás, 1985). The slices were maintained at $33-35^{\circ} \mathrm{C}$ throughout the recording procedure.

Recording procedure. Micropipettes were pulled from $1 \mathrm{~mm}$ o.d. borosilicate Omegadot glass tubing (World Prccision Instruments, New Haven, CT) using a Flaming-Brown P-80/PC microelectrode puller. The electrodes were filled with one of the following solutions: (1) $10 \%$ Lucifer yellow in distilled water, (2) 5\% Lucifer yellow in $1 \mathrm{~m}$ lithium acetate, or (3) $3 \mathrm{~m}$ potassium acetate. Although the highest level of intracellular staining for studying neuronal morphology could be achieved using electrodes containing only Lucifer yellow dissolved in distilled water, the resultant electrodes had very high resistances (over $200 \mathrm{M} \Omega$ ), which affected the quality of the electrophysiological recordings. On the other hand, reducing the electrode resistance by adding lithium chloride to the Lucifer yellow solution (Stewart, 1978) is known to modify $\mathrm{Cl}^{-}$mediated synaptic events, and the use of $\mathrm{Cl}^{-}$-containing pipettes has been reported to alter coupling between cells in the retina (Lasater and Dowling, 1985a). In addition, GABAergic drugs have been shown to affect junctional communication in the rctina (Piccolino et al., 1982). Therefore, in experiments examining the correlation between dye coupling and electrophysiological correlates of electrotonic coupling, lithium acetate was used to decrease the resistance of the dye-filled electrodes. Dissolving 5\% Lucifer yellow in $1 \mathrm{~m}$ lithium acetate provided electrodes with stable electrical characteristics and comparatively low resistances $(100-210 \mathrm{M} \Omega)$, but that were still effective in yielding intensely stained neurons. The criteria for assessing stability of cell penetration with these electrodes included the presence of a resting membrane potential of at least $-45 \mathrm{mV}$ and spike amplitudes of $50 \mathrm{mV}$ or more. However, since it is unknown whether lithium itself can affect coupling, only cells stained using Lucifer yellow dissolved in distilled water were scored for dye coupling.

Electrode potentials were amplified by a headstage connected to a NeuroData intracellular amplifier (NeuroData IR-183). Current was injected through a bridge circuit integral to the amplifier, and the amplitude of current injected and the resultant electrode potentials were observed on line on an analog storage oscilloscope (Kikusui COS 5020ST) in addition to being continuously digitized by a NeuroData Neurocorder (DR-886) and stored on VHS videotapes for subsequent off-line analysis. For data analysis a CED1401 Intelligent Laboratory Interface (Cambridge Electronic Design, Cambridge, UK) connected to a Compaq 386 computer was used, with hard copies obtained by directing the output to a Hewlett-Packard $7475 \mathrm{~A}$ digital plotter. In addition, data were digitized using a Microstar interface board (MicroStar Laboratories, Bellevue, WA) prior to storage and off-line analysis using a UNIXbased workstation (Apollo Series 400, Hewlett-Packard). The workstation, equipped with custom-designed software (NEUROSCOPE), was utilized during intracellular current injection and in afferent pathway stimulation to drive the stimulator, in addition to collecting, analyzing, and printing poststimulus data.

Electrical stimulation. Bipolar stimulating electrodes were gently placed either on the subcortical white matter near the anterior pole of the accumbens, or on the bed nucleus of the stria terminalis in proximity to the posterior region of the shell. Stimulating electrodes were constructed from a pair of $50-\mu \mathrm{m}$-diameter enamel-coated nichrome wires twisted together and with $1 \mathrm{~mm}$ of insulation removed from the tips. Stimulating pulses with durations of $100-500 \mu \mathrm{sec}$ and intensities between $50 \mu \mathrm{A}$ and $1.1 \mathrm{~mA}$ were delivered using a Grass $\mathrm{S} 88$ stimulator and a Grass PSIU6 constant current stimulus isolator. All recording and stimulating locations were identified by visual landmarks according to a stereotaxic rat brain atlas (Paxinos and Watson, 1986).

Pharmacological studies. Drugs were applied to the slices by adding them to the superfusion media. The following drugs were used in this study: apomorphine ( 5 or $50 \mu \mathrm{M}$; Sigma, St. Louis, MO), SCH 23390 [3 $\mu \mathrm{M}$; Research Biochemicals Inc. (KBI), Nattick, MA], SCH 39166 (3 $\mu \mathrm{M}$; Schering-Plough, Bloomfield, NJ), SKF 38393 (3 $\mu \mathrm{M}$; RBI), quinpirole $(10 \mu \mathrm{M}$; RBI), sulpiride (10 $\mu \mathrm{M}$; Sigma), and clozapine ( $3 \mu \mathrm{M}$; Sandoz, East Hanover, NJ). Drugs were prepared the same day that they were to be used. A high-concentration stock solution was first prepared by dissolving the drugs in distilled water, with the exceptions of sulpiride, which required the addition of one or two drops of lactic acid (solution pH: 5.5) in order to dissolve in distilled water, and clozapine, which was first dissolved in $0.1 \mathrm{~N} \mathrm{HCl}$, after which the solution was adjusted to $\mathrm{pH} 4.8$ by adding $10 \mathrm{~N} \mathrm{NaOH}$. Final working solutions were then made by diluting appropriate amounts of these stock solutions in physiological saline. The $\mathrm{pH}$ of the resultant control and drug-containing perfusion fluids was maintained between 7.35 and 7.45 by adding 
small amounts of $\mathrm{NaOH}(10 N)$ or $\mathrm{HCl}(1 N)$. The $\mathrm{pH}$ of the perfusion medium within the recording chamber was monitored using an indwelling microprobe connected to a $\mathrm{pH}$ meter $(\mathrm{pH}-1$, Microelectrodes, Inc). Ascorbic acid $(0.02 \%$; Sigma) was added in order to prevent oxidation of apomorphine, but did not produce an effect on accumbens neurons when it was administered alone $(n=26)$. The rationale for using apomorphinc instead of dopamine is that apomorphine is more stable in a neutral, oxygenated solution than is DA, and also should penetrate the tissue more rapidly since it is not subject to uptake into catecholamine terminals.

Lucifer yellow staining. After a neuron within the accumbens was impaled and the membrane potential had stabilized, Lucifer yellow was injected by applying 1-2 nA constant hyperpolarizing current interrupted by $20 \mathrm{msec}, 1 \mathrm{nA}$ depolarizing pulses delivered at $2-4 \mathrm{~Hz}$ to prevent the electrode tip from clogging. The dye was injected for 1-30 min, after which the slices were fixed overnight in $10 \%$ buffered formalin, washed in saline, and cleared by placing them in $100 \%$ dimethyl sulfoxide (DMSO) for at least $20 \mathrm{~min}$ (Grace and Llinás, 1985). Slices were then placed on microscope slides, coverslipped in DMSO, and examined with an epifluorescence microscope (Leitz Orthoplan 2). The dyc was observed using custom-designed filter cubes optimized for Lucifer yellow fluorescence characteristics (Omega Optical, Brattleboro, VT; excitation bandpass, $370-490 \mathrm{~nm}$; suppression lowpass, $510 \mathrm{~nm}$; dichromatic mirror at $45^{\circ}, 500 \mathrm{~nm}$ ). In order to compare frequency distribution of dye coupling between cells in treated and control slices, the data were analyzed using the Fisher exact test (Siegel and Castellan, 1988).

$D A$-depleted rats. A subset of slices was obtained from four additional rats in which endogenous DA had been depleted. This was accomplished by administering reserpine $(5 \mathrm{mg} / \mathrm{kg}$, s.c.) $24 \mathrm{hr}$ prior to decapitation and preparation of the slices for recording, and incubating the slices with $\alpha$-methyl-p-tyrosine ( $\alpha \mathrm{MPT} ; 100 \mu \mathrm{M}$ ) for at least $1 \mathrm{hr}$ prior to recording. In every depleted animal, as well as in three control rats, two slices (one containing exclusively the core region of the accumbens, and the other including only the shell region) were used for assessment of DA levels. These slices were sonicated in $0.1 \mathrm{~N}$ perchloric acid and 0.2 $\mathrm{mM} \mathrm{Na} \mathrm{S}_{2} \mathrm{O}_{5}(1 \mathrm{ml})$. The homogenates were centrifuged $(15 \mathrm{~min}$ at $50,000 \times g, 4^{\circ} \mathrm{C}$ ), the supernatants were analyzed for catecholamines, and the pellets were analyzed for tissue protein using the protein-dye binding method (Bradford, 1976). The supernatant fractions were assessed for DA and DOPAC content using high-performance liquid chromatography (HPLC) with electrochemical detection, as described previously (Keller et al., 1976).

\section{Results}

Intracellular recording and staining of neurons in nucleus accumbens core and shell regions

Recordings were made from brain slices obtained from 101 rats, in which 605 neurons were successfully labeled by intracellular injection of Lucifer yellow. Of those, 254 were located in the core region and 331 were in the shell region of the nucleus accumbens. Both regions of the accumbens were localized within the slice based on their relative position with respect to the anterior commissure, subcortical white matter, and the striatum, as assessed by comparison with a rat brain stereotaxic atlas (Paxinos and Watson, 1986). The regional location of every neuron within the accumbens was determined by visual inspection during intracellular injection and was confirmed in subsequent histological analysis of the stained cells. Twenty additional cells were also labeled, but the data were not included due to our inability to classify their location accurately to either the core or the shell region of the accumbens.
Characteristics of dye coupling between neurons in the nucleus accumbens

For each cell in which the impalement was sufficiently stable to allow injection of the dye for $1 \mathrm{~min}$ or longer, extensive labeling of the soma, dendrites, and local axon collaterals was observed. For $24 \%$ (22 of 91 ) of the cases in which a single accumbens neuron was injected with Lucifer yellow in control slices, subsequent histological examination revealed staining of two or more adjacent neurons (Fig. 1). Dye coupling was found to occur exclusively between neurons of the medium-sized spiny class; therefore, calculation of the incidence of coupling was based on the number of medium-sized spiny neurons stained. Overall, there was no significant difference in the incidence of dye coupling observed between neurons located in the core and those labeled in the shell region (Table 1). The somata of neurons exhibiting dye coupling were typically separated by up to 100 $\mu \mathrm{m}$, although in seven cases both somata were in close apposition. Out of the 585 neurons stained across all treatment groups, dye coupling was most commonly observed to occur between pairs of neurons $(n=76)$, but in 29 out of the total of 105 cases showing coupling, groups of three $(n=23)$, four $(n=5)$, or even five $(n=1)$ coupled cells were recovered after single injections (Fig. 1C).

In order to avoid labeling artifacts, only cells meeting the following set of criteria were counted as dye-coupled: (1) the cells were stable during the dye injection, and the injection was continued only as long as the cell membrane potential was maintained; (2) the intensity of staining was equivalent among the cluster of cells stained; and (3) there was no evidence of extracellular spillage of dye. In most cases the brief depolarizing pulses applied during injection triggered spikes, and neurons that fired spikes throughout the injection period typically displayed the most intense levels of staining. In addition, in every experiment and under each test condition, no cellular labeling was found when the dye was ejected into the extracellular space. This was also tested on 25 occasions when the extracellular ejection was performed immediately after the electrode was pulled from a cell that had not been injected with dye.

Among the diverse cell types observed, dye coupling was observed only between neurons exhibiting small somata (15.1 $\pm 2.5 \mu \mathrm{m}$ in diameter, mean $\pm \mathrm{SD}$ ) and densely spined dendrites. In addition, four other neuronal types were infrequently stained in both regions: medium or large aspiny neurons (32 in the shell and 11 in the core), large spinous neurons $(>20 \mu \mathrm{m}$ diameter; one in each region), sparsely spined neurons ( 9 in the shell and 1 in the core), and seven neurogliaform cells (all in the shell).

\section{Effects of $D A$ on dye coupling in the accumbens core}

In neurons located in the core region, perfusion for at least 5 min with physiological saline containing a low concentration (i.e., $5 \mu \mathrm{M}$ ) of the DA agonist apomorphine prior to intracellular recording and dye injection did not change the incidence of dye coupling from that observed in untreated slices (Table 1). In contrast, after the administration of higher doses of apomor-

\footnotetext{
Figure 1. Dye-coupled cells observed after injecting Lucifer yellow into single neurons in the core and in the shell regions of the accumbens. For each case in which cellular penetration was sufficiently stable to allow injection of the dye for longer than 1 min, neurons with well-stained somata, dendrites, and axons were recovered. $A$, Pair of neurons stained by injecting a single neuron with Lucifer yellow in the shell region. $B$, Pair of neurons stained in the core by injecting the dye into a single neuron. $C$, A case in which three cells were labeled after a single injection. Scale bar: $30 \mu \mathrm{m}$ for $A$ and $C, 50 \mu \mathrm{m}$ for $B$.
} 

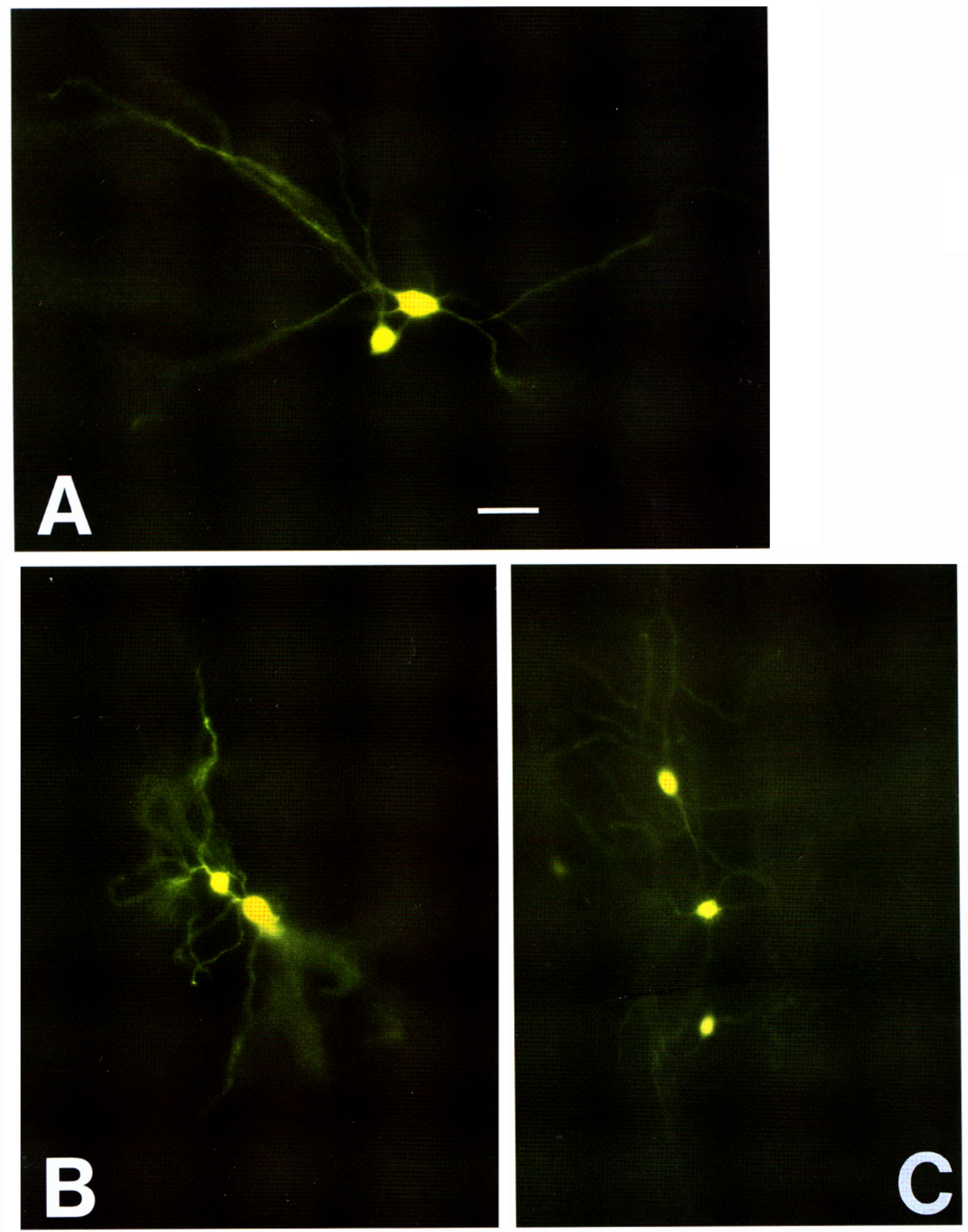
Table 1. Incidence of dye coupling between neurons in the core and in the shell regions of the accumbens

\begin{tabular}{|c|c|c|c|c|c|c|c|c|c|c|}
\hline & Control & Apo $5 \mu \mathrm{M}$ & Apo $50 \mu \mathrm{M}$ & SKF $3 \mu \mathrm{M}$ & $\begin{array}{l}\text { Apo } 50 \mu \mathrm{M} \\
+ \text { SCII } \\
23390\end{array}$ & $\begin{array}{l}\text { Apo } 50 \mu \mathrm{M} \\
+ \text { SCII } \\
39166\end{array}$ & $\begin{array}{l}\text { Quinp } \\
10 \mu \mathrm{M}\end{array}$ & $\begin{array}{l}\text { Apo } 50 \mu \mathrm{M} \\
+ \text { Sulp } \\
10 \mu \mathrm{M}\end{array}$ & $\begin{array}{l}\text { Apo } 50 \mu \mathrm{M} \\
1 \text { Cloz } \\
3 \mu \mathrm{M}\end{array}$ & $\begin{array}{l}\text { SKF } 3 \mu \mathrm{M} \\
1 \text { Sulp } \\
10 \mu \mathrm{M}\end{array}$ \\
\hline Corc & $\begin{array}{c}8 / 31 \\
(25.8 \%)\end{array}$ & $\begin{array}{c}2 / 13 \\
(15.4 \%)\end{array}$ & $\begin{array}{l}0 / 15 \\
(0 \%)\end{array}$ & $\begin{array}{l}0 / 14 \\
(0 \%)\end{array}$ & $\begin{array}{l}6 / 20 \\
(30 \%)\end{array}$ & $\begin{array}{l}6 / 19 \\
(31.6 \%)\end{array}$ & $\begin{array}{l}3 / 15 \\
(20 \%)\end{array}$ & $\begin{array}{l}A / 13 \\
(30.8 \%)\end{array}$ & $\begin{array}{l}0 / 13 \\
(0 \%)\end{array}$ & $\begin{array}{l}3 / 12 \\
(25 \%)\end{array}$ \\
\hline$p$ & & 0.372 & 0.030 & 0.037 & $0.494^{*}$ & $0.449^{* *}$ & 0.484 & $0.519 \dagger$ & 0.044 & $0.640 \ddagger$ \\
\hline Shell & $\begin{array}{l}14 / 60 \\
(23.3 \%)\end{array}$ & $\begin{array}{l}10 / 34 \\
(29.3 \%)\end{array}$ & $\begin{array}{l}7 / 31 \\
(22.6 \%)\end{array}$ & $\begin{array}{l}4 / 34 \\
(11.8 \%)\end{array}$ & $\begin{array}{l}8 / 24 \\
(33.3 \%)\end{array}$ & $\begin{array}{l}8 / 22 \\
(36.4 \%)\end{array}$ & $\begin{array}{l}9 / 24 \\
(37.5 \%)\end{array}$ & $\begin{array}{l}2 / 27 \\
(7.4 \%)\end{array}$ & $\begin{array}{l}3 / 28 \\
(10.7 \%)\end{array}$ & \\
\hline$p$ & & NS & NS & NS & NS & NS & NS & 0.133 & 0.085 & \\
\hline
\end{tabular}

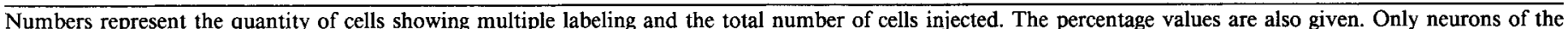

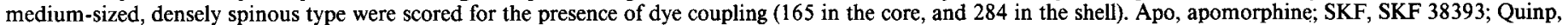

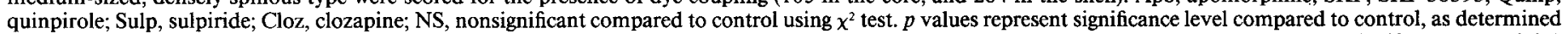

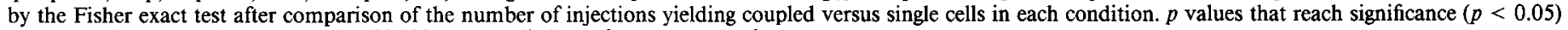
are in boldface. SCH 23390 and SCH 39166 were applied at a $3 \mu \mathrm{M}$ concentration.

$* p=0.017$ compared to apomorphine $50 \mu \mathrm{M}$.

** $p=0.020$ compared to apomorphine $50 \mu \mathrm{M}$.

$\dagger p=0.035$ compared to apomorphine $50 \mu \mathrm{M}$.

$\ddagger p=0.085$ compared to SKF $383933 \mu \mathrm{M}$.

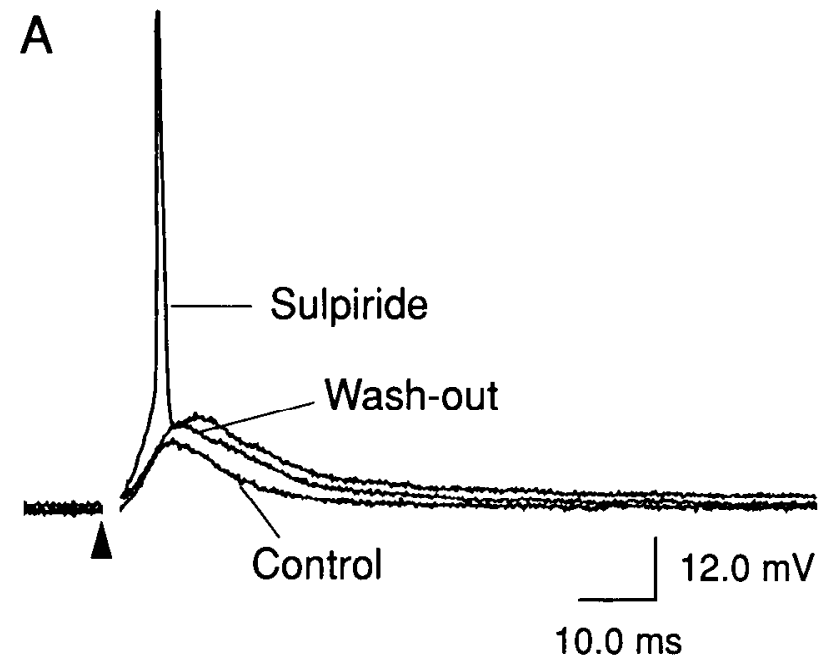

B

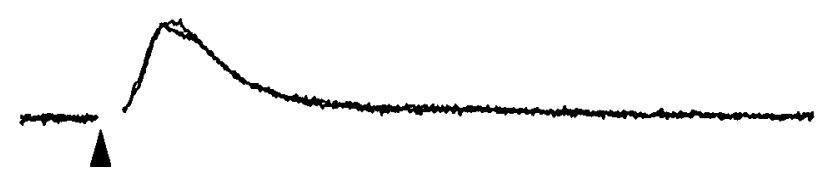

Figure 2. The effects of sulpiride on the response of a core neuron to cortical afferent stimulation. $A$, In control conditions, the amplitude of the stimulus current was set to $50 \%$ of that required to evoke a spike $(150 \mu \mathrm{A})$, and the resultant EPSP was recorded (control). After adding sulpiride $(10 \mu \mathrm{M})$ to the perfusion fluid, the same stimulus intensity evoked larger-amplitude EPSP, which occasionally triggered action potential discharge. After switching the perfusion back to physiological saline, the amplitude of the EPSP slowly returned to baseline levels. $B$, Overlay of two equal-amplitude EPSPs from the neuron recorded in $A$. One of the EPSPs was recorded in control conditions with $185 \mu \mathrm{A}$ stimulation, and the other was evoked using $110 \mu \mathrm{A}$ stimulation during perfusion with sulpiride. The finding that these equal-amplitude EPSPs have almost identical time courses suggests that the effect of sulpiride on EPSP amplitude is not mediatcd by an alteration in the mcmbrane conductance proximal to the EPSP, but instead is likely to be mediated presynaptically on the glutamatergic afferent terminal (Nisenbaum et al., 1992). In this and subsequent figures, the stimulus artifacts have been replaced by arrows for clarity. phine (i.e., $50 \mu \mathrm{M}$ ), no cases of dye coupling were observed out of 15 cells injected. The DA receptor subtype mediating this attenuation of coupling was examined by testing the effects of $D_{1}-$ and $D_{2}$-specific drugs. After administration of the $D_{1}$ agonist SKF $38393(3 \mu \mathrm{M})$, no coupled cells were observed out of 14 cells injected, and coadministration of either the $D_{1}$ antagonist SCH $23390(3 \mu \mathrm{M})$ or the newer, more specific $\mathrm{D}_{1}$ antagonist SCH $39166(3 \mu \mathrm{M})$ with $50 \mu \mathrm{M}$ apomorphine yielded similar levels of coupling as in control conditions (Table 1). In contrast, administration of the $D_{2} / D_{3}$ agonist quinpirole $(10 \mu \mathrm{M})$ did not alter the incidence of dye coupling from that observed in controls. However, if the slices were pretreated with the $\mathrm{D}_{2}$ antagonist sulpiride $(10 \mu \mathrm{M})$, the subsequent administration of $50 \mu \mathrm{M}$ apomorphine or $3 \mu \mathrm{M}$ SKF 38393 failed to produce the decrease in dye coupling observed with these agonists. In addition, clozapine administration did not alter the decrease in coupling induced by apomorphine (Table 1).

The finding that administration of the $\mathrm{D}_{2}$ blocker sulpiride was capable of altering the effect of the $D_{1}$ agonist on coupling suggested that it could be working by blocking a basal level of $\mathrm{D}_{2}$ receptor stimulation provided by endogenous DA that may be required for the $D_{1}$ effect. Therefore, electrophysiological recordings of corticoaccumbens evoked responses were examined for evidence of tonic $D_{2}$ stimulation. In the four cases examined, administration of sulpiride was found to cause a reversible increase in the evoked response (Fig. 2), an effect that is opposite to that produced by $\mathrm{D}_{2}$ agonists on evoked potentials (Calabresi et al., 1988, 1992). This effect of sulpiride could not be observed in the two cells examined in slices from DA-depleted rats (see Dye coupling in slices from DA-depleted rats, below). More recent data (O'Donnell and Grace, 1993b) suggest that the spontaneous release of DA that is present in the slice despite the absence of DA cell impulse flow is sufficient to exert a physiological effect on neurons in accumbens slices.

\section{Effects of dopaminergic drugs on dye coupling in the accumbens shell}

A total of 60 neurons were injected in the shell in untreated slices, with $23 \%$ of the injections resulting in the labeling of two 
Table 2. Modulation of dye coupling by DA in anterior versus posterior regions of the shell

\begin{tabular}{|c|c|c|c|c|c|c|c|c|c|}
\hline & Control & $\begin{array}{l}\text { Apo } \\
5 \mu \mathrm{M}\end{array}$ & $\begin{array}{l}\text { Apo } \\
50 \mu \mathrm{M}\end{array}$ & $\begin{array}{l}\text { SKF } \\
3 \mu \mathrm{M}\end{array}$ & $\begin{array}{l}\text { Apo } 50 \\
\mu \mathrm{M} \\
+\mathrm{SCH} \\
23390\end{array}$ & $\begin{array}{l}\text { Apo } 50 \\
\mu \mathrm{M} \\
+\mathrm{SCH} \\
39166\end{array}$ & $\begin{array}{l}\text { Quinp } \\
10 \mu \cdot \mathbf{M}\end{array}$ & $\begin{array}{l}\text { Apo } \\
50 \mu \mathrm{M} \\
+ \text { sulp } \\
10 \mu \mathrm{M}\end{array}$ & $\begin{array}{l}\text { Apo } 50 \\
\mu \mathrm{M} \\
+\mathrm{Cloz} \\
3 \mu \mathrm{M}\end{array}$ \\
\hline Anterior & $\begin{array}{l}7 / 20 \\
(35 \%)\end{array}$ & $\begin{array}{l}3 / 14 \\
(21.4 \%)\end{array}$ & $\begin{array}{l}1 / 16 \\
(6.3 \%)\end{array}$ & $\begin{array}{l}1 / 17 \\
(5.9 \%)\end{array}$ & $\begin{array}{l}3 / 13 \\
(21.4 \%)\end{array}$ & $\begin{array}{l}3 / 10 \\
(30 \%)\end{array}$ & $\begin{array}{l}3 / 12 \\
(25 \%)\end{array}$ & $\begin{array}{l}0 / 13 \\
(0 \%)\end{array}$ & $\begin{array}{l}2 / 13 \\
(15.4 \%)\end{array}$ \\
\hline$p$ & & 0.334 & 0.045 & 0.037 & $0.370^{*}$ & $0.560^{* *}$ & 0.427 & 0.018 & 0.203 \\
\hline Postcrior & $\begin{array}{l}1 / 17 \\
(5.9 \%)\end{array}$ & $\begin{array}{l}4 / 13 \\
(30.8 \%)\end{array}$ & $\begin{array}{l}5 / 13 \\
(41.7 \%)\end{array}$ & $\begin{array}{l}2 / 12 \\
(16.7 \%)\end{array}$ & $\begin{array}{l}5 / 11 \\
(45.5 \%)\end{array}$ & $\begin{array}{l}5 / 12 \\
(41.7 \%)\end{array}$ & $\begin{array}{l}6 / 11 \\
(54.5 \%)\end{array}$ & $\begin{array}{l}2 / 13 \\
(15.4 \%)\end{array}$ & $\begin{array}{l}1 / 15 \\
(6.7 \%)\end{array}$ \\
\hline$p$ & & 0.094 & 0.039 & 0.367 & 0.022 & 0.030 & 0.007 & $0.376 \dagger$ & $0.726 \ddagger$ \\
\hline
\end{tabular}

Comparison of incidence of dye coupling between cells located in the anterior region and those located in the posterior region of the accumbens shell. Calculation of values and statistical procedures are described in Table 1 , as are abbreviations. $p$ values represent significance level compared to control, as determined by the Fisher exact test after comparison of the number of injections yielding coupled versus single cells in each condition.

$* p=0.223$ compared to apomorphine $50 \mu \mathrm{M}$.

** $p=0.142$ compared to apomorphine $50 \mu \mathrm{M}$.

$\dagger p=0.189$ compared to apomorphine $50 \mu \mathrm{M}$.

$\ddagger p-0.055$ compared to apomorphine $50 \mu \mathrm{M}$.

or more neurons (Table 1). The incidence of dye coupling in slices perfused with apomorphine ( 5 or $50 \mu \mathrm{M})$ was not significantly different from that found in untreated slices. Similarly, administration of the $D_{2} / D_{3}$ agonist quinpirole or the $D_{1}$ agonist SKF 38393 was also ineffective in altering the incidence of dye coupling (Table 1). However, evaluation of the data in terms of the location of the cells injected (i.e., by analyzing the data according to whether the neurons were located unequivocally in either the anterior or the posterior parts of the shell) revealed a region-specific heterogeneity in dye coupling (Table 2) that is obscured when the shell region is analyzed as a single structure. Thus, the basal level of coupling was lower in cells injected in the posterior region of the shell when compared to the anterior region (i.e., posterior: $6 \%, 1$ of 17 ; anterior: $35 \%, 7$ of $20 ; p=$ 0.037 , Fisher exact test). Perfusion with either $50 \mu \mathrm{M}$ apomorphine or the $D_{1}$ agonist SKF 38393 caused a significant decrease in the incidence of coupling in the rostral portion of the shell, whereas administration of the $D_{2}$ agonist quinpirolc into the superfusion fluid did not alter the level of coupling in the rostral aspect of the shell (Table 2). However, the decrease in coupling observed in this region when $50 \mu \mathrm{M}$ apomorphine was applied could not be blocked by coadministration of the $\mathrm{D}_{2}$ antagonist sulpiride, suggesting that, unlike in the core region, there is no evidence that $D_{2}$ receptor stimulation is required to observe a $D_{1}$ receptor-mediated effect. In contrast, the incidence of coupling observed when clozapine was coadministered with apomorphine was not significantly different from control (Table 2).

On the other hand, perfusion of the slices with $50 \mu \mathrm{M}$ apomorphine resulted in a significant increase in coupling between neurons in the caudal portion of the accumbens shell. However, administration of lower ("presynaptic") doses of apomorphine $(5 \mu \mathrm{M})$ did not result in a statistically significant increase in coupling in this region (Table 2). This apomorphine-induced increase in coupling could be mimicked by perfusion with quinpirole, although perfusion with SKF 38393 did not alter the incidence of coupling observed in this subregion. Furthermore, although both sulpiride and clozapine reversed the apomorphine-induced increase in coupling in the posterior shell region, only sulpiride was effective in reversing the apomorphine-mediated decrease in coupling found in the core.

\section{Dye coupling in slices from $D A$-depleted rats}

The experiments outlined above suggest that a background level of $\mathrm{D}_{2}$ receptor stimulation is both present and necessary to observe the $D_{1}$-mediated decrease in coupling. This putative contribution of basal $D_{2}$ stimulation was tested in slices in which the DA had been depleted. This was done by pretreating the rats with reserpine and $\alpha \mathrm{MPT}$, as described in Materials and Methods, prior to preparing brain slices for recording. DA was depleted by approximately $92 \%$ in the core (control, $102.6 \pm$ $21.2 \mathrm{ng} / \mathrm{mg}$ protein; reserpine, $8.3 \pm 1.3 \mathrm{ng} / \mathrm{mg}$ protein) and $95 \%$ in the shell (control, $106.8 \pm 52.2 \mathrm{ng} / \mathrm{mg}$ protein; reserpine, $4.8 \pm 0.8 \mathrm{ng} / \mathrm{mg}$ protein), as measured $24 \mathrm{hr}$ after reserpine administration. Although there was no difference in DA levels between core and shell samples $(t=0.12$, Student's $t$ test), the remaining DA in depleted shell tissue was significantly lower than that in core samples ( $p<0.01 ; t=4.49$; Student's $t$ test). Furthermore, the actual D $\Lambda$ levels present in depleted slices during recording and staining are likely to be substantially lower, since this measure does not take into account the effects of the synthesis inhibitor, which was added to the reserpine-treated slices $1 \mathrm{hr}$ before initiating the recordings.

Intracellular injection of 59 neurons in the core region of slices obtained from DA-depleted rats yielded a similar level of dye coupling as that observed in slices from control rats $(22 \%, 4$ of

Table 3. Effects of selective DA agonists on dye coupling in the core of DA-depleted rats

\begin{tabular}{lllll} 
& $\begin{array}{l}\text { Cells } \\
\text { in- } \\
\text { jected }\end{array}$ & \multicolumn{2}{l}{$\begin{array}{l}\text { Cells } \\
\text { coupled } \%\end{array}$} & Significance \\
\hline Control & 18 & 4 & $22 \%$ & \\
SKF 38393 3 $\mu \mathrm{M}$ & 18 & 4 & $22 \%$ & NS \\
SKF 38393 3 $\mu \mathrm{M}+$ & & & & \\
quinpirole $10 \mu \mathrm{M}$ & 23 & 0 & $0 \%$ & $p=0.030$
\end{tabular}

Data are number of injections yielding dye coupling in reserpine and $\alpha \mathrm{MPT}$ treated rats. Significance column refers to the comparison of the results obtained with administration of $D_{1}$ and $D_{2}$ agonists with those in control conditions. The Fisher exact test was employed. 
18; Table 3). Furthermore, when the $\mathrm{D}_{1}$ agonist SKF 38393 was added to the perfusate, no change in the incidence of coupling was observed. However, perfusion with both SKF 38393 and the $\mathrm{D}_{2}$ agonist quinpirole caused a large and statistically significant reduction in the incidence of dye coupling observed (decrease to $0 \%, 0$ of $23 ; p=0.03$; Table 3 ).

Electrophysiological properties of stained neurons: correlations with dye coupling

In studies in which correlations between cell electrophysiology and dye coupling were made, a subset of 18 neurons (12 in the core, 6 in the shell) were recorded and stained using electrodes in which the Lucifer yellow had been dissolved in $1 \mathrm{M}$ lithium acetate in order to obtain maximal signal-to-noise ratio. Data from these cells were not included in the estimations of extent or pharmacological modulation of dye coupling, due to the unknown effects of increased lithium concentrations on this parameter. The cells recorded exhibited an averaged resting membrane potential of $-57.9 \pm 8.7 \mathrm{mV}$ (mean $\pm \mathrm{SD}$; range, -48 to $-74.7 \mathrm{mV}$ ) and an average input resistance of $98.9 \pm 34.2$ $\mathrm{M} \Omega(n=11 ; 60-160 \mathrm{M} \Omega)$, and upon depolarization of the membrane elicited spikes that averaged $60.3 \pm 12.5 \mathrm{mV}(50-88 \mathrm{mV})$ in amplitude. Each of the electrophysiological characteristics previously observed in accumbens neurons using standard potassium acetate electrodes, such as the presence of a slow depolarization preceding spikes, spike adaptation during depolarization, and low-threshold spikes (O'Donnell and Grace, 1991b, 1993a), was also observed using the lithium acetate electrodes. The only difference observed using these dye-filled electrodes compared to what had been described previously using potassium acetate-filled pipettes was the apparent absence of an afterhyperpolarization and presence of an afterdepolarization in approximately $50 \%$ of the cells recorded.

In 17 recordings from core neurons (12 using lithium acetate with Lucifer yellow and 5 with electrodes containing potassium acetate), the cortical afferents innervating this region of the accumbens were activated by stimulating the white matter locatcd at the antcrior surfacc of the accumbens, where the afferents to the accumbens from the prelimbic region of the prefrontal cortex are known to traverse (Sesack et al., 1989). Stimulation of the white matter $(0.1-1 \mathrm{~mA}, 0.1-0.5 \mathrm{msec}$ pulse duration) evoked EPSPs in 17 core cells at a latency of $4.0 \pm$ $1.3 \mathrm{msec}$, with peak EPSP amplitude averaging $8.7 \pm 3.2 \mathrm{mV}$ and occurring $6.9 \pm 2.0 \mathrm{msec}$ after the stimulus. Increasing the amplitude of the afferent fiber stimulation was sufficient to evoke action potential discharge, with spike thresholds averaging -52.1 $\pm 8.5 \mathrm{mV}$. Six shell neurons were activated by stimulation of the bed nucleus of the stria terminalis, which is believed to provide excitatory drive to this region via activation of the afferents to the accumbens arising from the bed nucleus as well as from the amygdala. EPSPs were evoked at a latency of 4.4 $\pm 1.2 \mathrm{msec}$, and had a peak amplitude of $10.8 \pm 6.6 \mathrm{mV}$. In three cases, increasing the amplitude of stimulation elicited action potentials. These responses are consistent with those reported previously for shell neurons (Pennartz and Kitai, 1991; Pennartz et al., 1992; O'Donnell and Grace, 1993a).

Evidence for electrical coupling between core neurons. When single stimuli were applied to cortical afferents to core neurons, an early component of the action potential waveform was observed in $35 \%$ ( 6 of 17 ) of the cells recorded. This component was apparently distinct from the initial segment-somatodendritic (IS-SD) break, since (1) it occurred as a spike prepo- tential, whereas the putative SD spike in these neurons typically occurs after the peak of the IS spike (O'Donnell and Grace, 1993a) (Fig. 3A), and (2) it had a varying temporal relationship with respect to the other spike components, even when the baseline membrane potential and spike amplitude were constant. Furthermore, when afferents are stimulated at an intensity just below spike threshold, on occasion ( 2 of 17) an all-or-none, small-amplitude (8-24 mV) spikelet was evoked without triggering action potential discharge (Fig. $3 B$ ). The probability of observing these spikelets could be increased by delivering a conditioning stimulus $10-50 \mathrm{msec}$ prior to the test stimulus, which has been shown to inhibit spike discharge evoked by the second stimulus both in the striatum (Nisenbaum et al., 1988) and in the accumbens (O'Donnell and Grace, 1991a, 1993a). Using this paradigm, stimuli that failed to evoke full-amplitude action potentials were frequently observed to elicit small-amplitude spikelets. Furthermore, this paired-pulse triggering of spikelets was found to occur in all the neurons tested that exhibited the early fast prepotential component of the action potential waveform ( 6 out of 17 cells studied in the core). In each case, these small spikes were distinct from evoked EPSPs since the rcpolarizing phasc of the spikclet had a much faster timc course than would be predicted from the membrane time constant (Fig. 4). Thus, unlike the passive decay associated with synaptic events, the spikelets repolarized via an active process (Coombs et al., 1955; Grace and Bunney, 1983). In each neuron that displayed these spikelets or fast prepotentials, subsequent staining with Lucifer yellow revealed that the neurons also exhibited dye coupling $(n=5)$.

Evidence for electrical coupling between shell neurons. Electrophysiological recordings from the shell region also provided indirect evidence for electrical coupling. Thus, stimulation of amygdaloid afferents evoked EPSPs in cells located in the shell region. Furthermore, in two out of six cases this stimulation also evoked distinct spikelets (Fig. $5 A$ ). Depolarizing the membrane during stimulation caused a decrease in the amplitude of the EPSPs; nonetheless, with sufficient levels of depolarization the stimulation was capable of triggering a full spike at the peak of the spikelet, with the spikelet now apparent as a fast prepotential (Fig. $5 B$ ). Differentiation of the waveforms of the full action potentials triggered in depolarized neurons by afferent stimulation revealed the presence of a small-amplitude spike component that (1) occurs early in the spike (i.e., prior to its peak), and (2) occurs at variable intervals prior to the peak of the spike, even when the baseline membrane potential is constant (Fig. 5B). Similar short-latency spikelets were also observed in eight additional core and shell neurons in which the attempted dye injection failed to label successfully the neuron recorded. However, all neurons exhibiting spikelets and that were stained with Lucifer yellow exhibited dye coupling, whereas two cells showing dye coupling did not exhibit fast prepotentials.

Finally, the possibility that the spikelets were IS spikes activated antidromically in the cell recorded was ruled out by cxperiments showing that the spikelet is still evoked by afferent stimulation even when the stimulus is delivered within $2 \mathrm{msec}$ of the spike (Fig. $6 F ; n=3$ ). Since this latency is shorter than that associated with stimulus-evoked spikelets, this failure of collision shows that the spikelet was not triggered antidromically along the same axon that carried the propagating action potential.

Activation of $D_{1}$ receptors prevents the observation of spikelets 

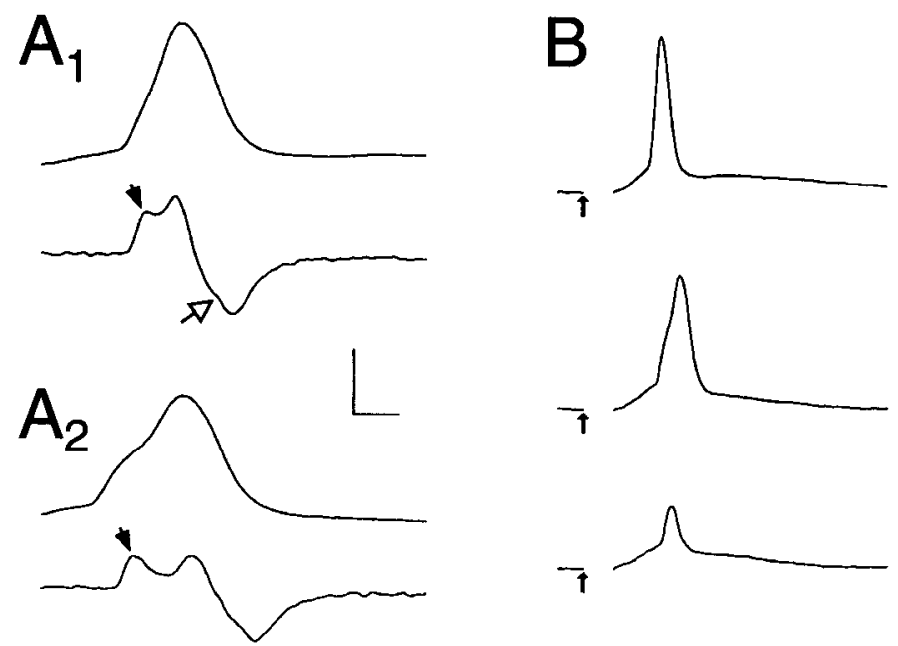

Figure 3. Action potential components and fast prepotentials recorded in accumbens core neurons. The tracings in this figure were obtained minutes before injection of Lucifer yellow into the neuron, which was subsequently shown to be dye-coupled (illustrated in Fig. $1 A$ ). $A_{I}$, Waveform of an action potential evoked by cortical afferent stimulation and recorded in a core neuron (upper trace). Differentiation of the waveform reveals the presence of an early component of the waveform (lower trace, solid arrow), which can be distinguished from the putative ISSD break (open arrow) that has been shown to occur late in the action potential waveform (O'Donnell and Grace, 1993a). $A_{2}$, In recordings obtained from the same neuron, a different action potential waveform is recorded (upper trace) which, after differentiation (lower trace), is found to exhibit a much longer latency between the fast prepotential and the spike. $B$, Examples of three evoked responses recorded in the same neuron with stimulation of excitatory afferents at threshold stimulation levels for evoking a spike. The traces show the variable latency between the EPSP and the spike, and also show a spikelet triggered in the absence of a full action potential. Calibration: $25 \mathrm{mV}, 1 \mathrm{msec}$ for $A ; 25 \mathrm{mV}, 3 \mathrm{msec}$ for $B$.

in core neurons. In three of the core cells showing spikelets in response to the second pulse in the paired-impulse paradigm, the addition of a $3 \mu \mathrm{M}$ concentration of the $\mathrm{D}_{1}$ agonist SKF 38393 to the superfusion fluid produced two primary effects: (1) a moderate amplitude depolarization of the membrane (by 10-15 mV), and (2) elimination of the spikelets that had been

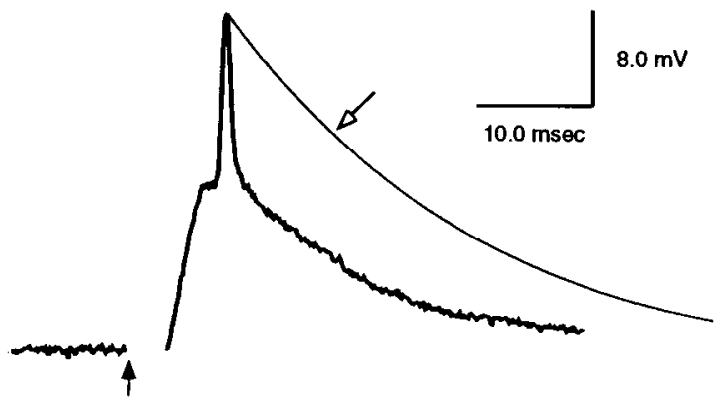

Figure 4. Unlike synaptic potentials that decay passively from their peak level of membrane depolarization, coupling potentials are known to repolarize at a much faster rate than would be predicted from the membrane time constant. This tracing shows the evoked response in a core neuron to stimulation of cortical afferent fibers, yielding an EPSP and a $12 \mathrm{mV}$ spikelet. The repolarization rate expected for a passive decay in this cell was calculated from the membrane time constant for this neuron $(\tau=10.2 \mathrm{msec}$; open arrow) and overlaid with the spikelet repolarization. The calculated passive decay occurs at a much slower rate than the repolarization of the spikelet, but is nonetheless roughly consistent with the rate of repolarization of the evoked EPSP.

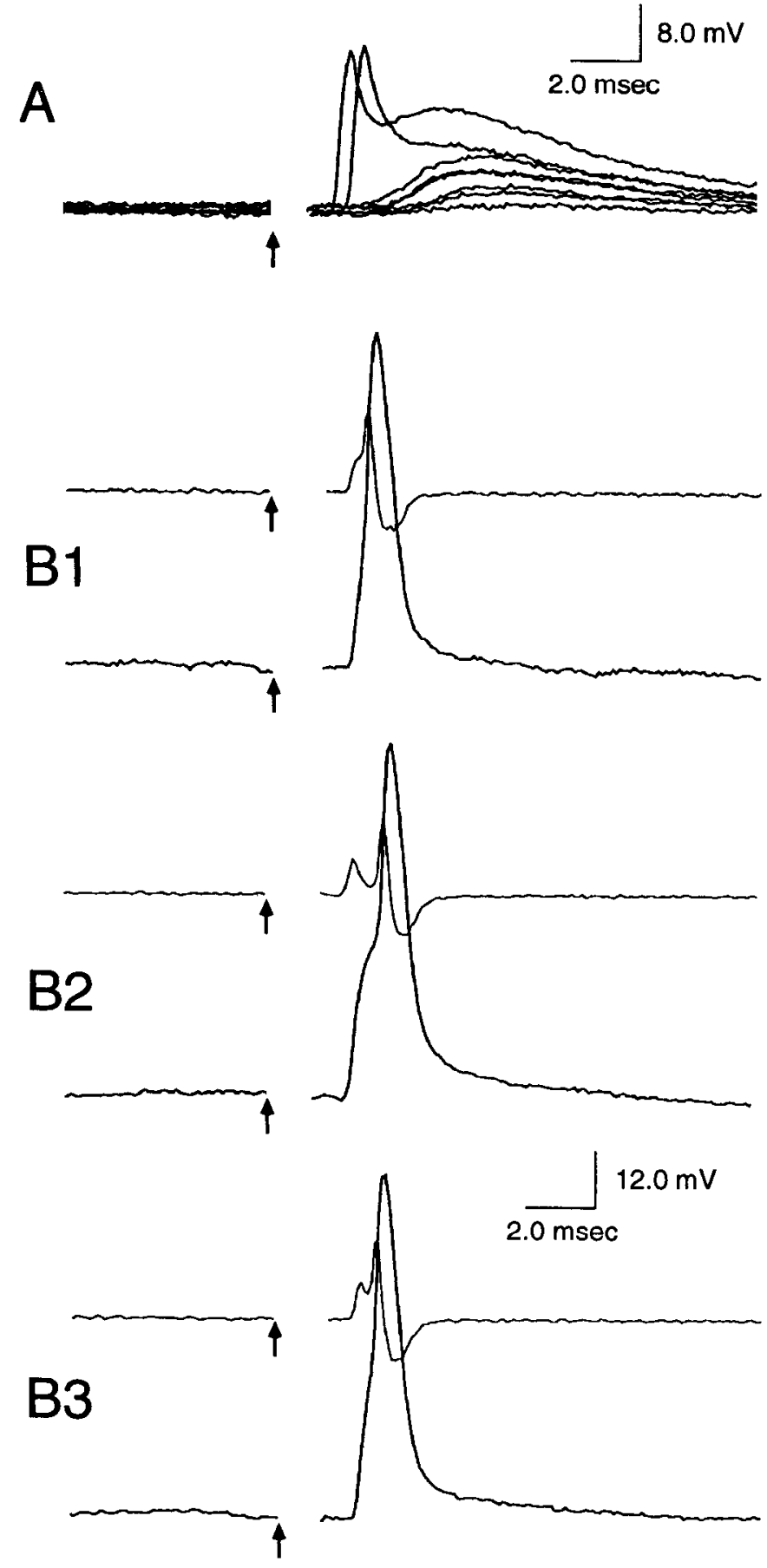

Figure 5. Evoked responses recorded from a neuron located in the shell region of the accumbens. $A$, Stimulation of amygdaloid afferents evokes an EPSP, and with increasing stimulus strength a fast spikelet. The latency of the spikelet in this case was shorter than that of the onset of the EPSP. The spikelets were evoked at a variable latency after the stimulus, and are therefore not likely to represent direct antidromic activation of the neuron impaled. Resting membrane potential, -74 $\mathrm{mV} . B 1-B 3$, In the same neuron at a depolarized membrane potential ( $-65 \mathrm{mV}$ at $+0.15 \mathrm{nA}$ constant current injection), a full spike could be evoked by afferent fiber stimulation. The fast prepotential was observed at the same latency as the spikelet shown in $A$. Furthermore, as observed for core neurons, the evoked responses recorded in this shell neuron (lower trace of each pair) exhibit a variable latency between the fast prepotential and the action potential, which can be readily observed when the waveforms are differentiated (upper traces of each pair). 

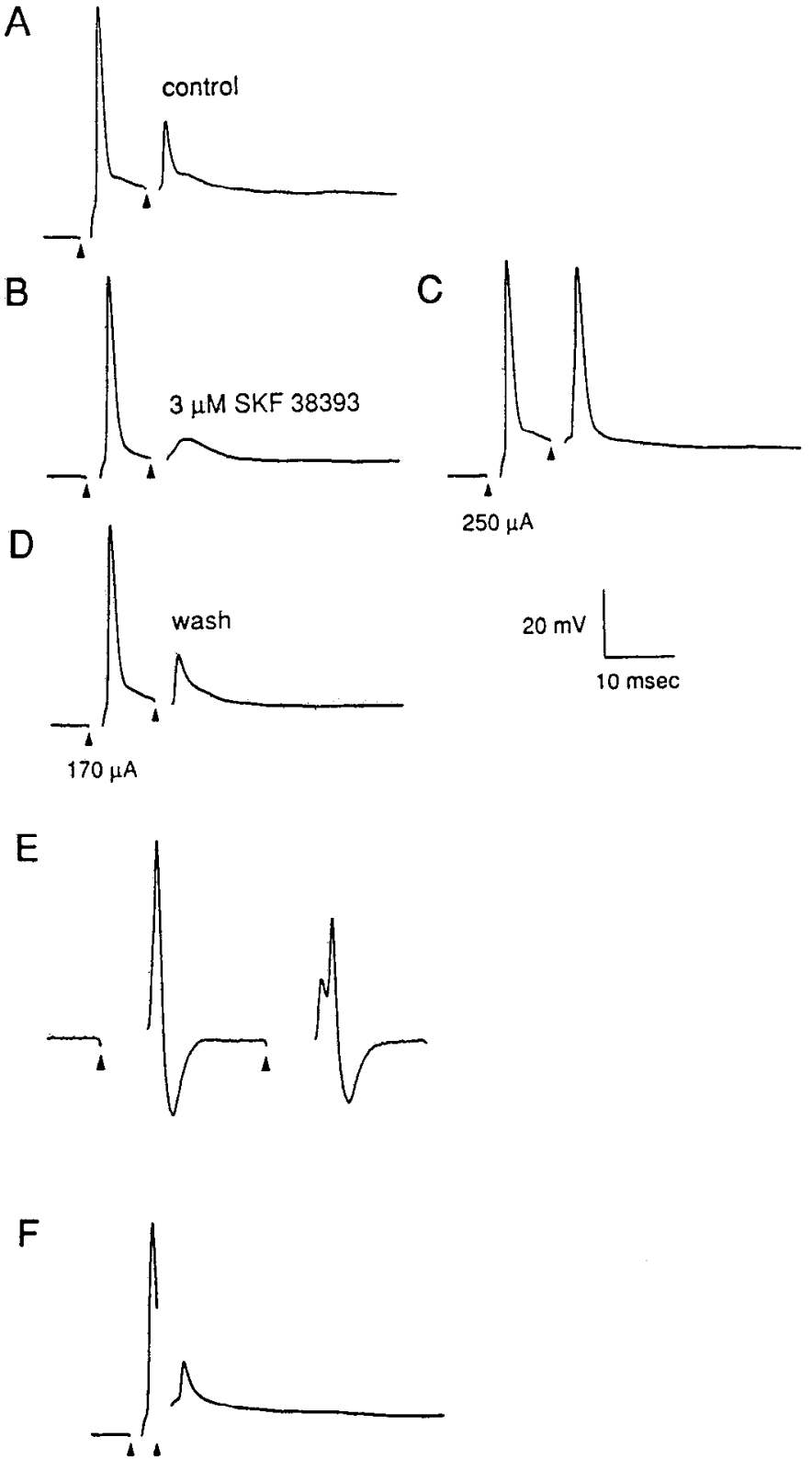

Figure 6. Fast spikelet discharge is not observed in core neurons after $\mathrm{D}_{1}$ receptor stimulation. $A, \mathrm{~A}$ stimulus delivered to the white matter anterior to the accumbens evokes a spike. When a second response is evoked during the inhibitory period following the first pulse (i.e., 10 msec interstimulus interval; O'Donnell and Grace, 1993a), a smallamplitude, fast spikelet is observed. The addition of the $D_{1}$ agonist SKF $38393(3 \mu \mathrm{M})$ to the superfusion fluid depolarized the membrane of this cell from a resting potential of $-75 \mathrm{mV}$ to a postdrug potential of -66 $\mathrm{mV}$. B, After SKF 38393 treatment, the spikelet is no longer evoked by the stimulus. $C$, Increasing the stimulus intensity results in a full spike in response to the second pulse. $D$, Within $8 \mathrm{~min}$ after switching the superfusion media to control physiological saline, spikelet discharge could again be evoked, although the membrane potential remained at the depolarized level (i.e., $-66 \mathrm{mV}$ ). Membrane potential returned to baseline levels approximately $35 \mathrm{~min}$ after changing to the drug-free media. Based on this difference in time course, it appears that the $D_{1}$ agonist may affect spikelet discharge and membrane potential via different mechanisms. $E$, Differentiation of the waveform recorded during high-intensity stimulation in the presence of SKF 38393 (shown in $C$ ) reveals an early component of the action potential evoked by the second stimulus. $F$, When the interpulse interval was reduced to cause the second pulse to be delivered during the repolarization of the evoked action potential (stimulus intensity, $170 \mu \mathrm{A}$ ), the spikelet is still elicited, showing that it did not collide with the initial spike. consistently evoked at these stimulating parameters prior to SKF 38393 application (Fig. 6A-D). Increasing the stimulus amplitude did not restore the spikelet, but instead evoked a full action potential. However, in this condition the SD component of the spike was shifted with respect to the IS spike (Fig. $6 E$ ), resulting in a waveform that appeared to be associated with a coupling potential. Since the threshold for the early component under these conditions was identical to that of the full spike, it is more likely that this early component represents a temporal shift of the IS spike. This possibility is further substantiated by the observation that, although the $D_{1}$ agonist is capable of completely blocking the spikelet, it does not alter the threshold for action potential generation (control, $-49.8 \pm 3.3 \mathrm{mV}$; SKF $38393,-52 \pm 5.6 \mathrm{mV}$ ), again showing that the generation of the spikelet is independent of the IS spike, which determines the action potential threshold of the neuron (Coombs et al., 1957; Grace, 1990). The paired-pulse-evoked spikelets were restored approximately 6-12 min after washout of the drug by perfusion with control physiological saline. However, the $D_{1}$ induced membrane depolarization did not return to basal levels until $35 \mathrm{~min}$ or more following drug washout.

\section{Discussion}

The differences between core and shell regions of the accumbens in terms of their connectivity pattern and neurotransmitter content have been well established (Heimer et al., 1991). Thus, studies have substantiated that these regions are heterogeneous with respect to the origin of their afferents (Berendse et al., 1992a) as well as in their efferent projections (Zahm and Heimer, 1990; Heimer et al., 1991; Berendse et al., 1992b). For example, the majority of tyrosine hydroxylase-positive synaptic boutons have been reported to contact the dendritic shafts of neurons in the shell, whereas in the core these synapses preferentially contact dendritic spines (Zahm, 1992). Also, differences have been reported in the morphology of medium spiny neurons from both subregions (Meredith et al., 1992; O'Donnell and Grace, 1993a). Furthermore, neurochemical and pharmacological disparities between the core and shell regions of the accumbens have been shown, which include the higher content of ChATlike (Meredith et al., 1989), cholecystokinin-like (Záborszky et al., 1985), and neurotensin-like immunoreactivities (Zahm and Heimer, 1988) in the shell region, as well as the higher concentration of $D_{2}$ receptors in the core subdivision (Jongen-Rêlo et al., 1991). These anatomical and neurochemical distinctions may also alter the response properties of these systems to pharmacological treatment, such as in the region-specific differences in the response of accumbens cells to neuroleptic administration (Deutch and Cameron, 1992).

The primary neuronal type labeled in this study in both core and shell regions was the medium-sized densely spinous neuron, which bears a strong resemblance to the morphology of striatal medium spiny neurons. This finding is consistent with the results of Golgi studies in the accumbens (Chronister et al., 1981; DeFrance et al., 1985), which show that medium spiny neurons comprise the predominant cell type in the accumbens. A much smaller proportion of aspiny neurons, as well as a variety of sparsely spinous cells and a few neurogliaform cells, comprise the balance of neurons in this region.

\section{Dye coupling between accumbens neurons}

In this study, accumbens neurons were found to share another property with striatal cells, that is, that of dye coupling and its 
modulation by DA (Ccpeda et al., 1989; Onn et al., 1991). Nonetheless, the present experiments show that both the extent of coupling and its pharmacological regulation appear to be substantially different in the accumbens. Indeed, DA appears to exert distinct actions on dye coupling within different $s u b$ divisions of the accumbens as well.

Although most investigators agree that it is necessary to perform freeze-fracture electron microscopy to demonstrate conclusively the presence of gap junctions and that proof of the existence of electrical coupling requires the use of simultaneous intracellular recording from two coupled cells (Llinás, 1985), such approaches are not typically feasible in the vertebrate CNS. Thus, because of the inherent technical difficulty in using these techniques to establish the presence of gap junctions and electrical coupling, most of the recent studies of cellular interactions within the mammalian CNS have relied primarily on the presence of dyc coupling to assay for such interactions. However, as several authors have pointed out (Llinás, 1985; Gutnick and Lobel-Yaakov, 1986), unless sufficiently restrictive criteria are employed in collecting and analyzing the results of cell labeling, this technique can be prone to artifact. Thus, we implemented several precautions to decrease the chance that labeling artifacts would enter into our observations. Because of its higher sensitivity and its propensity to yield lower-noise electrodes, several investigators have used staining based on biocytin or neurobiotin to test for the presence of coupling between cells (Kita and Armstrong, 1991; Vaney, 1991). However, since biocytin is known to be taken up from the extracellular space into damaged and undamaged fibers and can be transported retrogradely into cell bodies (Chevalier et al., 1992; McDonald et al., 1992), this stain is likely to be less reliable for rigorous dye coupling tests. Furthermore, dye coupling as revealed by Lucifer yellow injection has becn shown repcatedly to correlate with elcctrical coupling under well-controlled conditions (Andrew et al., 1981; Gutnick and Prince, 1981; MacVicar and Dudek, 1981; Connors et al., 1983; Grace and Bunney, 1983; Kettenmann et al., 1983; Walsh et al., 1989; Eghbali et al., 1990, 1991b; Núñez et al., 1990), whereas biocytin has not as yet been subjected to such analysis. Therefore, Lucifer yellow was used to assess dye coupling in this study because (1) it is not taken up from the extracellular space, (2) it is not transported retrogradely from axon terminals or dendritic fields, and (3) only cells remaining viable throughout the Lucifer yellow injection procedure appear to be capable of retaining the dye. Furthermore, only cells that had sufficient label to outline their dendritic field and adequately label the dendritic spines, if present, were scored for incidence of dye coupling. Dye uptake from the extracellular space into damaged neurons was ruled out as a potential source of artifact, since in several experiments dye that had been ejected into the extracellular space did not stain neurons even in cases in which the ejection was done immediately after withdrawing the pipette from a cell that had not been injected $(n=25)$. Almost all of the cells in this sample were maintained in a stable condition throughout the period of recording and dye injection, and on many occasions action potentials were elicited throughout the injection process. Also, for each case in which dye coupling was found, a region of dendritic overlap between the coupled neurons could be shown. Finally, the fact that the incidence of coupling can be substantially altered by administering moderate concentrations of dopaminergic drugs provides substantial evidence that the coupling observed here cannot be attributed to artifact.
Overall, the dye coupling data and electrophysiological evidence support the existence of a direct molecular and electrical link between sets of neurons in both core and shell regions of the nucleus accumbens, which suggests the presence of gap junctions. Although direct evidence does not as yet exist, one potential observation that may be indicative of the anatomical substrate of coupled cell clusters could be the isolated but dense clusters of neurons reported to be present in these regions (Herkenham et al., 1984; Meredith et al., 1989; Zoli et al., 1990; Groenewegen et al., 1991). Furthermore, a high level of close perikaryal apposition is reported to occur within each cluster (Paskevich et al., 1991). Indeed, the incidence of coupling determined using in vitro recordings from neurons in the core and in the shell (26\% and $23 \%$, respectively) was higher than that observed in the striatum in vitro (9\%; Cepeda et al., 1989), but is within the range found for in vivo striatal recordings (18\%; Onn et al., 1991). The presence of dye coupling between neurons mediated via gap junctions is also supported by studies showing that the mRNA for gap junctional subunits (i.e., connexin) is present throughout the striatal complex, including the accumbens (Matsumoto et al., 1991). There is also the possibility that the close membrane appositions described in the accumbens by Domesick (Domesick, 1981; Paskevich et al., 1991) are indicative of a close functional coupling with respect to their activity as well.

The incidence of coupling reported here from an in vitro preparation is not necessarily similar to what would be found in vivo. Indeed, in a slice preparation almost all excitatory afferents to these neurons have been severed, and our findings might represent a "basal" state of coupling between these neurons in the absence of their normal inputs, and indicate that it is likely that the capacity for coupling is present in a majority of neurons.

\section{Dopaminergic modulation of dye coupling in the accumbens}

Dye coupling between neurons in the accumbens is not a static phenomenon. Instead, in a manner that is analogous to dye coupling observed in the retina (Teranishi et al., 1983; Piccolino et al., 1984) and in the striatum (Cepeda et al., 1989; Onn et al., 1991), the extent of dye coupling between accumbens cells is under dynamic regulation by the DA system. However, the pharmacology of this modulation is both unique and, to the extent of our current knowledge, considerably more complex in the accumbens when compared with other vertebrate brain regions studied to date. Furthermore, dye coupling between neurons located in each of the anatomically defined subdivisions of the accumbens is affected by $D_{1}$ and/or $D_{2}$ receptor stimulation in a unique way. In this series of studies, the drugs to be tested are added to the superfusion media at the given concentrations at least $5 \mathrm{~min}$ before Lucifer yellow injection, with the drug present continuously until the slice is fixed at the end of the experiment. In this way, the relative concentrations of drugs added can be precisely controlled under equilibrium conditions.

Recent neurochemical studies have shown the accumbens shell to be a heterogeneous structure (Groenewegen et al., 1991; Berendse et al., 1992a), with significant differences occurring between anterior and posterior regions of this nucleus (Henselmans and Stoof, 1991; Jongen-Rêlo et al., 1991; Voorn and Docter, 1992). There are several reports of rostrocaudal gradients of several neurochemical markers within the accumbens, such as $D_{2}$ receptor binding (Bardo and Hammer, 1991), the efficacy of quinpirole in inhibiting $\mathrm{ACh}$ release (Henselmans 
and Stoof, 1991), and the presence of DA-stimulated pre-proenkephalin mRNA (Voorn and Docter, 1992). However, one difficulty in comparing results between preparations is that several studies have distinguished only between anterior and posterior accumbens, possibly including proportions of the core and shell regions in each sample. Our results, however, were obtained only from cells unambiguously located either in the core, in the anterior part of the shell, or in the posterior part of the shell. Indeed, 20 cases of stained neurons were not analyzed due to the inability to localize them preciscly to one of these subregions. The recording electrodes were placed so as to avoid the rostral pole of the nucleus accumbens, in which the core and shell divisions cannot easily be distinguished (Heimer et al., 1991; Zahm and Brog, 1992; Zahm and Heimer, 1992). However, since these boundaries are not quite clear, it is likely that the anterior shell group may also include neurons from the medial rostral pole. Those cells were included since they showed similar results as those in the shell, and the medial aspect of the rostral pole has been reported to be shell-like in nature (Zahm and Brog, 1992). The most dorsal region of the shell located close to the ventricle and the septum, which has been referred to as the cone (Groenewegen et al., 1991; Heimer et al., 1991; Deutch et al., 1992), was not examined in this study due to its distinct neurochemical and anatomical characteristics. Therefore, by subdividing the accumbens into distinct domains on the basis of anatomical and neurochemical parameters, the effects of selective DA drugs on dye coupling were found to be much more consistent.

The precise site of action of DA cannot be determined from our data. Although DA effects could be mediated indirectly, it is not likely given (1) known direct effects in other brain regions (Piccolino et al., 1984; Lasater and Dowling, 1985a), and (2) the absence of spontaneously firing neurons in accumbens slices (O'Donnell and Grace, 1993a). Furthermore, $D_{2}$ effects in the posterior shell region are not due to presynaptic inhibition of DA release, since actions of $D_{2}$ antagonists and $D_{1}$ agonists are consistent with postsynaptically mediated responses.

\section{$D_{1}$ receptor stimulation decreases coupling in the core}

In studies of coupling performed in the core region of the accumbens, $D_{1}$ receptor stimulation consistently decreases the incidence of dye coupling, since (1) direct stimulation of $D_{1}$ receptors by the $D_{1}$ agonist SKF 38393 resulted in a significantly lower incidence of coupling; (2) only the highest concentration of apomorphine tested, which should have been adequate to stimulate the less-sensitive $D_{1}$ receptor (Richfield et al., 1989), decreased the incidence of dye coupling; and (3) the attenuation of coupling caused by high doses of apomorphine was blocked by pretreatment with two different $\mathrm{D}_{1}$ antagonists (SCH 23390 or $S C H$ 39166). In contrast, stimulation of the $D_{2}$ receptor by administration of the $D_{2}$ agonist quinpirole or by application of a low concentration of apomorphine $(5 \mu \mathrm{M})$, which should only activate $\mathrm{D}_{2}$ receptors in the high-affinity state (Richfield et al., 1989), did not change the degree of coupling from control levels. Nonetheless, it is apparent that $\mathrm{D}_{2}$ receptors may still exert some regulatory influence over dye coupling in the core. Treatment with the $\mathrm{D}_{2}$ antagonist sulpiride $(10 \mu \mathrm{M})$ prevented both high doses of apomorphine as well as SKF 38393 from inducing a decrease in the incidence of coupling (Table 1). Therefore, it appears that some basal level of $\mathrm{D}_{2}$ stimulation produced by endogenous DA was necessary to allow $D_{1}$ receptor stimu- lation to decrease coupling. This was substantiated in experiments showing that DA depletion will prevent the decrease in dye coupling produced by $D_{1}$ receptor stimulation. Furthermore, coadministration of both a $D_{1}$ and a $D_{2}$ agonist to the DA-depleted slice restored the $\mathrm{D}_{1}$-dependent attenuation of coupling (Table 3 ). The presence of a tonic $\mathrm{D}_{2}$ receptor stimulation by endogenous DA in the slice is further confirmed in experiments examining the effects of the $\mathrm{D}_{2}$ antagonist sulpiride on the corticoaccumbens stimulation-evoked potential. Thus, given that these cortical afferents are known to have $\mathrm{D}_{2}$ receptors on their terminals (Robertson, 1977; Magnusson et al., 1987) and that $\mathrm{D}_{2}$ agonist administration will reduce the evoked EPSP (Calabresi et al., 1992), the finding that sulpiride caused a reversible increase in the amplitude of the EPSP evoked by stimulation of cortical afferents clearly supports the presence of tonic $\mathrm{D}_{2}$ receptor stimulation in the core region in untreated slices. Taken together, these data support the following model for DA modulation of dye coupling in the accumbens core: (1) $D_{1}$ stimulation reduces coupling, but only if some threshold level of $D_{2}$ stimulation is present; (2) there is a sufficient amount of extracellular DA in the accumbens slice to supply a tonic level of $\mathrm{D}_{2}$ receptor stimulation (but not $\mathrm{D}_{1}$ stimulation) in the core region, even in the apparent absence of DA cell axonal impulse flow. For this reason, administration of $\mathrm{D}_{2}$ agonists to control slices, where a basal level of $D_{2}$ receptor stimulation is present, would not be expected to affect coupling whereas $D_{2}$ antagonists would prevent the $D_{1}$-induced inhibition of coupling. This is functionally analogous to studies showing that combined $D_{1}$ and $D_{2}$ receptor stimulation is required to evoke a maximal response to either drug (Clark and White, 1987; Williams and Woolverton, 1990).

\section{Coupling in the rostral and caudal portions of the shell is differentially affected by $D A$}

Although the incidence of dye coupling in the shell occurs at roughly the same extent as that found in the core, it appears to be under a distinct type of pharmacological regulation. Initial analysis of the effects of dopaminergic drugs on accumbens shell neurons failed to reveal any statistically significant effect of DA on coupling. Thus, the incidence of dye coupling was not altered by perfusion of the slices with apomorphine $(5$ or $50 \mu \mathrm{M})$, or with SKF 38393. On this basis, the effects of drugs on dye coupling were analyzed separately for neurons that could be unequivocally located in the anterior part of the shell region versus those clearly localized in the posterior shell. Using this paradigm, the effects of DA receptor stimulation on coupling between neurons in the anterior part of the accumbens shell were found to be roughly similar but less pronounced than those observed in core neurons, with one exception: unlike the core, there was no evidence of an interdependence between $D_{1}$ and $D_{2}$ receptor stimulation within either section of the shell. Furthermore, although the basal level of coupling present between neurons located in the posterior part of the accumbens shell was low in control slices, $\mathrm{D}_{2}$ receptor activation by apomorphine (50 $\mu \mathrm{M})$ or quinpirole caused a significant increase in coupling. These $\mathrm{D}_{2}$-mediated effects were blocked by first administering sulpiride, or the $D_{2} / D_{4}$ antagonist clozapine. In contrast, neither the $D_{1}$ agonist nor the $D_{1}$ antagonist was effective in altering the basal level of coupling or the increased coupling induced by apomorphine in this region. 
Indirect evidence for electrical coupling in the core and shell regions

The criteria of dye coupling for identifying gap junctions between neurons can be strengthened if an independent measure of coupling can be correlated with the anatomical data. One technique that has been used in several vertebrate systems (Baker and Llinás, 1971; Llinás et al., 1974; MacVicar and Dudek, 1981; Taylor and Dudck, 1982; Grace and Bunney, 1983; Piccolino et al., 1984; Dudek and Snow, 1985; Cepeda et al., 1989) as an adjunct to dye coupling is based on physiological recordings, since this measure not only can supply an independent assessment of junctional conductance, but also can examine whether the coupling has a functional impact on the physiology of the neurons examined. Four separate physiological observations were made that are consistent with the presence of electrical coupling: (1) the presence of evoked spikelets that, unlike EPSPs (Coombs et al., 1955), repolarize faster than would be predicted for a passive decay derived from the membrane time constant; (2) the failure to collide the spikelets with synaptically evoked spike discharge, showing that the spikelets were not activated antidromically in the neuron recorded; (3) the 100\% correlation between cells exhibiting coupling potentials with those neurons subsequently shown to be dye-coupled; and (4) the ability to block pharmacologically the activation of putative coupling potentials with drugs shown to interrupt dye coupling.

The putative coupling potentials can be distinguished from fast excitatory synaptic events by examining their time course; that is, an EPSP is known to decay from its peak potential via a passive process, with the rate of repolarization being a function of the membrane time constant $(\tau)$. In contrast, since coupling potentials are proposed to reflect action potentials occurring in the coupled neuron, the repolarization occurs via an active process, and therefore decays much faster than would be predicted by $\tau$. In addition, in several neurons this spikelet is observed to trigger an action potential, in which case it is observed as a fast prepotential (Walsh et al., 1989). This fast prepotential occurs during earlier time points in the spike waveform than is characteristic for the IS component (O'Donnell and Grace, 1993a). Furthermore, it is unlikely that these spikelets are IS spikes from the recorded cell that failed to induce an SD component, since IS spikes exhibit a high safety factor in accumbens cells (O'Donnell and Grace, 1993a). The probability of observing the spikelet in isolation is increased if evoked action potential generation is inhibited, such as during the inhibitory period following the test pulse in a paired-impulse stimulation paradigm using short (i.e., 10-50 msec) interpulse intervals.

Finally, the putative coupling potential appears to be regulated by the same factors that control dye coupling. Thus, administration of the $D_{1}$ agonist SKF 38393 consistently blocks the triggering of spikelets observed after the second of a pair of pulses is delivered at short interstimulus intervals in core cells. SKF 38393 elicits two effects on core neurons: a membrane depolarization, and the suppression of evoked spikelet discharge. The suppression of spikelet was reversed within 6-12 min of washout of the drug; however, the $D_{1}$-triggered cell membranc depolarization persisted for over $35 \mathrm{~min}$. The slower recovery of the membrane potential suggests that spikelet suppression and depolarization may be mediated via different mechanisms.
Examination of the effects of clozapine on DA modulation of dye coupling in the accumbens

Sulpiride, a $\mathrm{D}_{2}$ blocker, prevented the apomorphine-induced decrease in dye coupling in the core in addition to blocking the apomorphine-induced increase in coupling between shell neurons. In contrast, although the highly effective neuroleptic clozapine, like sulpiride, did block apomorphine actions on caudal shell neurons, it did not prevent the effects of apomorphine in the core. Furthermore, in the rostral shell, clozapine prevented the apomorphine-mediated decrease in coupling, thereby resembling the effect of the $D_{1}$ antagonists in this region, which contrasted with the actions of sulpiride. In an analogous manner, clozapine has been recently shown to increase c-fos expression in the shell, but not in the core region of the accumbens (Deutch et al., 1992). Although the clinical potency of APDs (antipsychotic drugs) has been correlated with their efficacy in blocking $\mathrm{D}_{2}$ receptors (Seeman, 1987), the affinity of clozapine for these receptors is low (Seeman, 1987). Nonetheless, chronic treatment with clozapine has a high efficacy against both positive and negative symptoms (Kane et al., 1988).

While it is unclear whether this difference between clozapine and $\mathrm{D}_{2}$ antagonists, which resemble classic APDs in their pharmacology, is of functional significance, it is possible that this difference can be related to the different therapeutic actions of classic and atypical APDs. Although the primary difference between clozapine and classic APDs is related to the absence of extrapyramidal side effects with clozapine treatment, evidence indicates that this distinction is related to their different feedback effects on nigrostriatal DA neuron firing with chronic treatment; that is, repeated administration of classic APDs causes DA cell depolarization block in the nigrostriatal but not the mesolimbic DA system (see Grace, 1992, for review). Indeed, the distinct projection patterns of core and shell efferents appear to be consistent with this hypothesis. Thus, development of depolarization block requires an action on the striatal neurons projecting to the mesencephalic DA cells (Bunney and Grace, 1978; Chiodo and Bunney, 1983; Grace, 1992). Moreover, spiny neurons in the core project primarily to the DA cells located in the substantia nigra pars compacta, whereas the DA neurons preferentially targeted by shell projections are located in the anterior ventral tegmental (VTA) region (Heimer et al., 1991). Therefore, one model of APD action is that clinically effective classical and atypical APDs cause depolarization block in VTA DA cells via their actions in the shell, whereas the classical (but not atypical) APDs cause extrapyramidal side effects via their blockade of DA in the core of the accumbens.

In summary, the common thcrapcutic actions of clozapine and typical APDs appear to correlate best with induction of depolarization block in the mesolimbic DA cells (Chiodo and Bunney, 1983; Grace, 1992) to alleviate positive symptoms (Grace, 1991). However, classical and atypical APDs also differ with respect to their therapeutic actions, in that whereas both are effective in reducing the hyperdopaminergic-related positive symptoms, only clozapine is highly effective against negative symptoms as well. Furthermore, unlike positive symptoms, the negative symptoms appear to be related to a DA deficiency, and are alleviated by treatment with DA agonists (Angrist et al., 1980, 1982; see Grace, 1991, 1992, for review). Although speculative, the unique ability of clozapine to block DA in the shell 
but not in the core may be related to its efficacy on both positive and negative symptoms, respectively.

\section{The role of coupling as it relates $t o$ information processing within the accumbens}

Although the role of electrotonic coupling in most brain regions is unclear, one area in which it is better understood is the retina. Studies of the retina have shown that DA modulation of coupling regulates dark adaptation (Teranishi et al., 1983; Lasater and Dowling, 1985b; Tornqvist et al., 1988) by altering the level of inhibitory influence between center-surround regions (Mangel and Dowling, 1985). In other brain areas, electrotonic coupling is thought to underlie synchronous firing or reciprocal excitation when the set of neurons coupled are spontaneously active (Bennett, 1977; Llinás, 1985). However, since electrotonic synapses tend to act like low-pass electrical filters between cells (Hagiwara and Morita, 1962; van Swigchem, 1981; Dudek et al., 1983), electrotonic coupling would be expected to reduce spike peaks substantially while allowing. slow changes in the membrane potential to pass without significant attenuation. Therefore, it is more likely that the electrical coupling would tend to equalize membrane potential differences between cells, causing a synchronization of their overall levels of activity. Indeed, electrotonic transmission would be one of the most direct ways that a population of inhibitory neurons could allow spread of excitation to a subset of neighboring neurons to synchronize their activity states. The function of such synchronized activity states could produce two unique functional effects on information processing within the accumbens, depending on the nature of the cells coupled together. For example, if cells that are electrically coupled receive similar parallel afferent connections from the same cortical regions, an enhancement of coupling between these neurons would produce additive effects on membrane depolarization, and thereby amplify the level of corticoaccumbens throughput. In contrast, if coupling is present between cells that normally receive nonoverlapping inputs from functionally distinct cortical regions, coupling could provide a means to integrate information arising from otherwise disparate suurces of afferent input. In addition, the potential for coupled cells to share second messengers could provide a means for an afferent input to trigger a prolonged development of longer-latency responses that may ultimately shape the responsivity of the network of coupled neurons.

Thus, in addition to its actions on the membrane conductances of single neurons, the dopaminergic system may also alter the network properties of neuronal assemblies within the basal ganglia in a more complex manner. The function of such a network may be related to the strategic role of the accumbens as a link between cognitive, limbic, and motor systems (Mogenson et al., 1980), where it can mediate the integration of affective states with sensorimotor processes. As such, a disturbance in the DA-mediated regulation of electrotonic coupling could conceivably account for several of the clinical manifestations occurring in psychiatric disorders related to this neurochemical system. As reviewed above, extrapolating from their distinct complements of afferent and efferent connections and neurotransmitter content, the core and shell regions are likely to subserve different functions within the CNS. The core region receives its primary excitatory drive from the prefrontal cortex and the hippocampus (DeFrance et al., 1985; Sesack et al., 1989; McDonald, 1991), and therefore, being an extension of the striatum, could be involved in more cognitive aspects of motor control, such as motor planning. On the other hand, the shell area receives glutamatergic input mainly from the amygdala, hippocampus, and entorhinal cortex (DeFrance et al., 1985; Sesack and Pickel, 1990); thus, it is more likely to be involved in the control of affective states.

Although highly spcculative, a modcl of psychopathological disturbance relating the well-characterized hyperdopaminergic state in animals and the classical profile in schizophrenia in humans may be drawn. Thus, a DA-mediated decrease in the comparatively high level of coupling present in the core could conceivably lead to a narrowing of cortical integration, possibly causing a restriction of behavioral choices, in a manner analogous to the DA-related behavior of perseverance (Evenden and Robbins, 1983), the inability to switch strategies (Matthysse, 1981), or the impaired attention states (Robbins, 1990) that are characteristics associated with the negative symptoms of this disorder. Conversely, a DA-induced increase in coupling, such as that observed in the posterior shell region, might enhance the ability of a group of cells to become activated from cortical or limbic afferents that otherwise may have a restricted influence within this subregion of the accumbens. In terms of the schizophrenic patient, an increascd ncuronal intcraction within these limbic circuits could be expressed as an expansion in the range of stimuli that can induce a predefined set of emotional responses, conceivably contributing to the positive symptoms (i.e., delusional constructs, thought disorder, inappropriate affect, and disorganized behavior), which are believed to arise from DA hyperactivity within the nucleus accumbens (Wyatt et al., 1988; Gray et al., 1991). Under such conditions, the ability of clozapine to block preferentially the DA-mediated increase in coupling in the posterior shell region, but not the DA-mediated decrease in coupling in the anterior shell and the core, could conceivably underlie its ability to alleviate the hyperdopaminergic-related positive symptoms via its actions in the shell, while at the same time improving the DA deficiency-related negative symptoms by allowing DA transmission in the core to occur normally.

\section{References}

Alheid GF, Heimer L (1988) New perspectives in basal forebrain organization of special relevance for neuropsychiatric disorders. The striatopallidal, amygdaloid, and corticopetal components of substantia innominata. Neuroscicnce 27:1-39.

Andrew RD, MacVicar BA, Dudek FE, Hatton GI (1981) Dye transfer through gap junctions between neuroendocrine cells on rat hypothalamus. Science 211:1187-1189.

Angrist BM, Rotrosen J, Gershon S (1980) Differential effects of amphetamine and neuroleptics on negative vs. positive symptoms in schizophrenia. Psychopharmacology 72:17-19.

Angrist BM, Peselow E, Rubinstein M, Corwin J, Rotrosen J (1982) Partial improvement in negative schizophrenia symptoms after amphetamine. Psychopharmacology 78:128-130.

Baker R, Llinás R (1971) Electrotonic coupling between neurones in the rat mesencephalic nucleus. J Physiol (Lond) 212:45-63.

Bardo MT, Hammer RPJ (1991) Autoradiographic localization of dopamine $D_{1}$ and $D_{2}$ receptors in rat nucleus accumbens: resistance to differential rearing conditions. Neuroscience 45:281-290.

Bennett MVL (1963) Electrotonic junctions between teleost spinal neurons: electrophysiology and ultrastructure. Science 141:262-264.

Bennett MVL (1977) Electrical transmission: a functional analysis and comparison to chemical transmission. In: Handbook of physiology, Sec 1, The nervous system, Vol I, Cellular biology of neurons, Pt 1 (Kandel ER, ed), pp 357-416. Bethesda, MD: American Physiological Society.

Bennett MVL, Spray DC, Harris AL (1981) Electrical coupling in development. Am Zool 21:413-427.

Berendse HW, Galis-de Graaf Y, Groenewegen HJ (1992a) Topo- 
graphical organization and relationship with ventral striatal compartments of prefrontal corticostriatal projections in the rat. J Comp Neurol 316:314-347.

Berendse HW, Groenewegen HJ, Lohman AHM (1992b) Compartmental distribution of ventral striatal neurons projecting to the mesencephalon in the rat. J Neurosci 12:2079-2103.

Bradford MM (1976) A rapid and sensitive method for the quantification of microgram quantities of protein utilizing the principle of protein-dye binding. Anal Biochem 72:248-254.

Bunney BS, Grace AA (1978) Acute and chronic haloperidol treatment: comparison of effects on nigral dopamine cell activity. Life Sci 23:1715-1728

Calabresi P, Benedetti M, Mercuri NB, Bernardi G (1988) Endogenous dopamine and dopaminergic agonists modulate synaptic excitation in neostriatum: intraccllular studics from naive and catecholaminedepleted rats. Neuroscience 27:145-157.

Calabresi P, De Murtas M, Mercuri NB, Bernardi G (1992) Chronic neuroleptic treatment: D2 dopamine receptor supersensitivity and striatal glutamatergic transmission. Ann Neurol 31:366-373.

Cepeda C, Walsh JP, Hull CD, Howard SG, Buchwald NA, Levine MS (1989) Dye coupling in the neostriatum of the rat. I. Modulation by dopamine-depleting lesions. Synapse 4:229-237.

Chevalier G, Deniau JM, Menetrey A (1992) Evidence that biocytin is taken up by axons. Neurosci Lett 140:197-199.

Chiodo LA, Bunney BS (1983) Typical and atypical neuroleptics: differential effects of chronic administration on the activity of A9 and A10 midbrain dopaminergic neurons. J Neurosci 3:1607-1619.

Chronister RB, Sikes RW, Trow TW, DeFrance JF (1981) The organization of nucleus accumbens. In: The ncurobiology of the nucleus accumbens (Chronister RB, DeFrance JF, eds), pp 97-146. Brunswick, ME: Hauer Institute.

Church J, Baimbridge KG (1991) Exposure to high-pH medium increases the incidence and extent of dye coupling between rat hippocampal CA1 pyramidal neurons in vitro. J Neurosci 11:3289-3295.

Clark D, White FJ (1987) Review: D1 dopamine receptor-the search for a function: a critical evaluation of the D1/D2 dopamine receptor classification and its functional implications. Synapse 1:347-388.

Comings DE (1987) A controlled study of Tourette syndrome. VII. Summary: a common genetic disorder causing disinhibition of the limbic system. Am J Hum Genet 41:839-866.

Connors BW, Bernardo LS, Prince DA (1983) Coupling between neurons of the developing rat neocortex. J Neurosci 3:773-782.

Coombs JS, Eccles JC, Fatt P (1955) Excitatory synaptic action in motoneurons. J Physiol (Lond) 139:374-395.

Coombs JS, Curtis DR, Eccles JC (1957) The interpretation of spike potentials of motoneurons. J Physiol (Lond) 139:198-231.

DeFrance JF, Marchand JF, Sikes RW, Chronister RB, Hubbard JI (1985) Characterization of fimbria input to nucleus accumbens. J Neurophysiol 54:1553-1567.

Deutch AY, Cameron DS (1992) Pharmacological characterization of dopamine systems in the nucleus accumbens core and shell. Neuroscience 46:49-56.

Deutch AY, Lee MC, Iadarola MJ (1992) Regionally specific effects of atypical antipsychotic drugs on striatal fos expression: the nucleus accumbens shell as a locus of antipsychotic action. Mol Cell Neurosci 3:332-341.

Domesick VB (1981) Further observations on the anatomy of nucleus accumbens and caudatoputamen in the rat: similarities and contrasts. In: The neurobiology of the nucleus accumbens (Chronister RB, DeFrance JF, eds), pp 7-39. Brunswick, ME: Hauer Institute.

Dudek FE, Snow RW (1985) Electrical interactions and synchronization of cortical neurons: electrotonic coupling and field effects. In: Gap junctions (Bennett MVL, Spray DC, eds), pp 325-336. Cold Spring Harbor, NY: Cold Spring Harbor Laboratory.

Dudek FE, Andrew RD, MacVicar BA, Snow RW, Taylor CP (1983) Recent evidence for a possible significance of gap junction and electrotonic synapses in the mammalian brain. In: Basic mechanisms of neural hyperexcitability (Elliott KAC, Jasper HH, VanGelder NM, eds), pp 31-73. New York: Liss.

Eghbali B, Kessler JA, Spray DC (1990) Expression of gap junction channels in communication-incompetent cells after stable transfection with cDNA encoding connexin 32. Proc Natl Acad Sci USA 87: 1328-1331.

Eghbali B, Kessler JA, Dougherty M, Hsu H, Chanson M, Spray DC (1991a) Expression of connexin 26 gap junction channels in cells with neuronal phenotype. Soc Neurosci Abstr 17:1334.
Eghbali B, Kessler JA, Reid LM, Roy C, Spray DC (1991b) Involvement of gap junctions in tumorigenesis: transfection of tumor cells with connexin 32 cDNA retards growth in vivo. Proc Natl Acad Sci USA 88:10701-10705.

Evenden JL, Robbins TW (1983) Increased response switching, perseveration, and perseverative switching following $d$-amphetamine in the rat. Psychopharmacology 80:67-73.

Furshpan EJ, Potter DD (1959) Transmission at the giant motor synapses of the crayfish. J Physiol (Lond) 145:289-325.

Gogan P, Gueritaud JP, Horcholle-Bossavit G, Tyc-Dumont S (1977) Direct excitatory interactions between spinal motoneurones of the cat. J Physiol (Lond) 272:755-767.

Grace AA (1990) Evidence for the functional compartmentalization of spike generating regions of rat midbrain dopamine neurons recorded in vitro. Brain Res 524:31-41.

Grace AA (1991) Phasic versus tonic dopamine release and the modulation of dopamine system responsivity: a hypothesis for the etiology of schizophrenia. Neuroscience 41:1-24.

Grace AA (1992) The depolarization block hypothesis of neuroleptic action: implications for the etiology and treatment of schizophrenia. J Neural Transm [Suppl] 36:91-131.

Grace AA, Bunney BS (1983) Intracellular and extracellular electrophysiology of nigral dopaminergic neurons -3 . Evidence for electrotonic coupling. Neuroscience 10:333-348.

Grace AA, Llinás R (1985) Morphological artifacts induced in intracellularly stained neurons by dehydration: circumvention using rapid dimethyl sulfoxide clearing. Neuroscience 16:461-475.

Grace AA, Onn S-P (1989) Morphology and electrophysiological properties of immunocytochemically identified rat dopamine neurons recorded in vitro. J Neurosci 9:3463-3481.

Gray JA, Feldon J, Rawlins JNP, Hemsley DR, Smith AD (1991) The neuropsychology of schizophrenia. Behav Brain Sci 14:1-84.

Groenewegen HJ, Berendse HW, Meredith GE, Haber SN, Voorn P, Wolters JG, Lohman AHM (1991) Functional anatomy of the ventral, limbic system-innervated striatum. In: The mesolimbic dopamine system: from motivation to action (Willner P, Scheel-Kruger J, eds), pp 19-59. New York: Wiley.

Gutnick MJ, Lobel-Yaakov R (1986) Coupling among neurons in neocortical slices: a specific response to dendrotomy. Exp Brain Res [Suppl] 13:9-17

Gutnick MJ, Prince DA (1981) Dye coupling and possible electrotonic coupling in the guinea pig neocortical slices. Science 211:67-70.

Hagiwara S, Morita H (1962) Elcctrotonic transmission between two nerve cells in leech ganglion. J Neurophysiol 25:721-727.

Heimer L, Zahm DS, Churchill L, Kalivas PW, Wohltmann C (1991) Specificity in the projection patterns of accumbal core and shell in the rat. Neuroscience 41:89-125.

Henselmans JML, Stoof JC (1991) Regional differences in the regulation of acetylcholine release upon $\mathrm{D}_{2}$ dopamine and $N$-methyl$\mathrm{D}$-aspartate receptor activation in rat nucleus accumbens and neostriatum. Brain Res 566:1-7.

Herkenham M, Moon Edley S, Stuart J (1984) Cell clusters in the nucleus accumbens of the rat, and the mosaic relationship of opiate receptors, acetylcholinesterase and subcortical afferent terminations. Neuroscience 11:561-593.

Jongen-Rêlo AL, Groenewegen HJ, Voorn P (1991) Compartmental organization of the rat nucleus accumbens: mu-opioid and dopamine D1 and D2 receptor distribution. Eur J Neurosci [Suppl] 4:2299.

Kane J, Honigfeld G, Singer J, Meltzer HY (1988) Clozapine for the treatment-resistant schizophrenics. Arch Gen Psychiatr 45:789-796.

Kaneko A (1971) Electrical connexions between horizontal cells in the dogfish retina. J Physiol (Lond) 213:95-105.

Keller R, Oke A, Mefford I, Adams RN (1976) Liquid chromatographic analysis of catecholamines: routine essay for regional brain mapping. Life Sci 19:995-1004.

Kettenmann H, Orkand RK, Schachner M (1983) Coupling among identified cells in mammalian nervous system cultures. J Neurosci 3:506-516.

Kita H, Armstrong W (1991) A biotin-containing compound N-(2aminoethyl)biotinamide for intracellular labeling and neuronal tracing studies: comparison with biocytin. J Ncurosci Methods 37:141150.

Lasater EM, Dowling JE (1985a) Dopamine decreases conductance of the electrical junctions between cultured retinal horizontal cells. Proc Natl Acad Sci USA 82:3025-3029.

Lasater EM, Dowling JE (1985b) Electrical coupling between pairs of 
isolated fish horizontal cells is modulated by dopamine and cAMP In: Gap junctions (Bennett MVL, Spray DC, eds), pp 393-404. Cold Spring Harbor, NY: Cold Spring Harbor Laboratory.

Llinás RR (1985) Electrotonic transmission in the mammalian central nervous system. In: Gap junctions (Bennett MVL, Spray DC, eds), pp 337-353. Cold Spring Harbor, NY: Cold Spring Harbor Laboratory.

Llinás R, Sugimori M (1980) Electrophysiological properties of in vitro Purkinje cell somata in mammalian cerebellar slices. J Physiol (Lond) 305:171-195.

Llinás R, Baker R, Sotelo C (1974) Electrotonic coupling between neurons in cat inferior olive. J Neurophysiol 37:560-571.

MacVicar BA, Dudek FE (1981) Electrotonic coupling between pyramidal cells: a direct demonstration in rat hippocampal slices. Science 213:782-785.

Magnusson O, Mohringe B, Fowler CJ (1987) Comparison of the effects of dopamine D1 and D2 receptor antagonists on striatal, limbic and nigral dopamine synthesis and utilization. J Neural Transm 69: 163-177.

Mangel SC, Dowling JE (1985) Responsiveness and receptive field size of carp horizontal cells are reduced by prolonged darkness and dopamine. Science 229:1107-1109.

Matsumoto A, Arai Y, Urano A, Hyodo S (1991) Cellular localization of gap junction mRNA in the neonatal rat brain. Neurosci Lett 124: 225-228.

Matthysse S (1973) Antipsychotic drug actions: a clue to the neuropathology of schizophrenia? Fed Proc 32:200-205.

Matthysse S (1981) Nucleus accumbens and schizophrenia, 1980. In: The neurobiology of the nucleus accumbens (Chronister RB, DeFrance JF, eds), pp 351-359. Brunswick, ME: Hauer Institute.

McDonald AJ (1991) Organization of amygdaloid projections to the prefrontal cortex and associated striatum in the rat. Neuroscience 44: $1-14$.

McDonald AJ, Mascagni F, Riley YD, Neal RL, Brinley-Reed M (1992) Biocytin injections produce selective neuronal labelling in the rat CNS. Neuroreport 3:337-340.

McMahon DG, Knapp AG, Dowling JE (1989) Horizontal cell gap junctions: single-channel conductance and modulation by dopamine. Proc Natl Acad Sci USA 86:7639-7643.

Meredith GE, Blank B, Groenewegen HJ (1989) The distribution and compartmental organization of the cholinergic neurons in nucleus accumbens of the rat. Neuroscience 31:327-345.

Meredith GE, Agolia R, Arts MPM, Groenewegen HJ, Zahm DS (1992) Morphological differences between projection neurons of the core and shell in the nucleus accumbens of the rat. Neuroscience 50:149-162.

Mogenson GJ, Jones DL, Yim CY (1980) From motivation to action: functional interface between limbic system and the motor system. Prog Neurobiol 14:69-97.

Moreno AP, Eghbali B, Spray DC (1991) Connexin 32 gap junction channels in stably transfected cells: unitary conductance. Biophys J 60:1254-1266.

Nisenbaum ES, Orr WB, Berger TW (1988) Evidence for two functionally distinct subpopulations of neurons within the rat striatum. $\mathbf{J}$ Neurosci 8:4138-4150.

Nisenbaum ES, Berger TW, Grace AA (1992) Presynaptic modulation by $\mathrm{GABA}_{\mathrm{B}}$ receptors of glutamatergic excitation and GABAergic inhibition of ncostriatal ncurons. J Neurophysiol 67:477-481.

Núñez A, Garcia-Austt E, Buño W (1990) In vivo electrophysiological analysis of Lucifer yellow-coupled hippocampal pyramids. Exp Neurol 108:76-82.

Oades RD, Halliday GM (1987) Ventral tegmental (A10) system: neurobiology. 1. Anatomy and connectivity. Brain Res Rev 12:117165.

O'Donnell P, Grace AA (1991a) Dye coupling is differentially affected by apomorphine in accumbens core and shell neurons. Soc Neurosci Abstr 17:456.

O'Donnell P, Grace AA (1991b) Physiology and incidence of dye coupling in nucleus accumbens neurons. Third IBRO World Congr Neurosci Abstr, p 146.

O'Donnell P, Grace AA (1993a) Physiological and morphological properties of accumbens corc and shell ncurons recorded in vitro. Synapse 13:135-160.

O'Donnell P, Grace AA (1993b) Tonic inhibition of corticoaccumbens terminals by $D_{2}$ receptors. Soc Neurosci Abstr, in press.

Onn S-P, Berger TW, Grace AA (1991) Dye coupling in type I and type II striatal neurons: alteration by apomorphine and localization to the patch/matrix. Soc Neurosci Abstr 17:850.

Parsons LH, Justice JB (1992) Extracellular concentration and in vivo rccovery of dopamine in the nucleus accumbens using microdialysis. J Neurochem 58:212-218.

Paskevich PA, Evans HK, Domesick VB (1991) Morphological assessment of neuronal aggregates in the striatum of the rat. J Comp Neurol 305:361-369.

Paxinos G, Watson C (1986) The rat brain in stereotaxic coordinates. Sydney: Academic.

Pennartz CMA, Kitai ST (1991) Hippocampal inputs to identified neurons in an in vitro slice preparation of the rat nucleus accumbens: evidence for feed-forward inhibition. J Neurosci 11:2838-2847.

Pennartz CMA, Dolleman-van der Weel MJ, Kitai ST, Lopes da Silva FH (1992) Presynaptic dopamine D1 receptors attenuate excitatory and inhibitory limbic inputs to the shell region of the rat nucleus accumbens studied in vitro. J Neurophysiol 67:1325-1334.

Piccolino M, Ncyton J, Witkovsky P, Gerschenfeld HM (1982) $\gamma$ Aminobutyric acid antagonists decrease junctional communication between L-horizontal cells of the retina. Proc Natl Acad Sci USA 79: 3671-3675.

Piccolino M, Neyton J, Gerschenfeld HM (1984) Decrease of gap junction permeability induced by dopamine and cyclic $3^{\prime}: 5^{\prime}$ monophosphate in horizontal cells of turtle retina. J Neurosci 4:24772488.

Ramón F, Zampighi GA, Rivera A (1985) Control of junctional permeability. In: Gap Junctions (Bennett MVL, Spray DC, eds), pp 155166. Cold Spring Harbor, NY: Cold Spring Harbor Laboratory.

Rao G, Barnes CA, McNaughton BL (1987) Occlusion of hippocampal electrical junctions by intracellular calcium injection. Brain Res 408 : 267-270.

Richfield EK, Penney JB, Young AB (1989) Anatomical and affinity state comparisons between dopamine $\mathrm{D} 1$ and $\mathrm{D} 2$ receptors in the rat central nervous system. Neuroscience 30:767-777.

Robbins TW (1990) The case for frontostriatal dysfunction in schizophrenics. Schizophr Bull 16:391-402.

Robertson HA (1977) Cerebral decortication reverses the effect of amphetamine on striatal D2 dopamine binding site density. Neurosci Lett 72:325-329.

Rose B, Loewenstein WP (1975) Permeability of cell junction depends on local cytoplasmic calcium activity. Nature 254:250-252.

Schmitt FO, Dev P, Smith BH (1976) Electrotonic processing of information by brain cells. Science 193:114-120.

Seeman P (1987) Dopamine receptors and the dopamine hypothesis of schizophrenia. Synapse 1:133-152.

Sesack SR, Pickel VM (1990) In the rat medial nuclcus accumbens, hippocampal and catecholaminergic terminals converge on spiny neurons and are in apposition to each other. Brain Res 527:266-279.

Sesack SR, Deutch AY, Roth RH, Bunney BS (1989) Topographical organization of the efferent projections of the medial prefrontal cortex in the rat: an anterograde tract-tracing study with Phaseolus vulgaris leucoagglutinin. J Comp Neurol 290:213-242.

Siegel S, Castellan NJ (1988) Nonparametric statistics for the behavioral sciences. New York: McGraw-Hill.

Snyder SH (1973) Amphetamine psychosis: a model of schizophrenia mediated by catecholamines. Am J Psychiatr 130:61-67.

Sotelo C, Korn H (1978) Morphological correlates of electrical and other interactions through low-resistance pathways between neurons of the vertebrate central nervous system. Int Rev Cytol 55:67-107.

Spray DC, White RL, Verselis V, Bennett MVL (1985) General and comparative physiology of gap junction channels. In: Gap junctions (Bennett MVL, Spray DC, eds), pp 139-153. Cold Spring Harbor, NY: Cold Spring Harbor Laboratory.

Stevens JR (1973) An anatomy of schizophrenia? Arch Gen Psychiatr 29:177-189.

Stewart WW (1978) Functional connections between cells as revealed by dye coupling with a highly fluorescent naphthalimide tracer. Cell 14:741-759.

Stewart WW (1981) Lucifer dyes. Highly fluorescent dyes for biological tracing. Nature 292:17-21.

Taylor CP, Dudek FE (1982) A physiological test for electrotonic coupling between CA1 pyramidal cells in rat hippocampal slices. Brain Res 235:351-357.

Teranishi T, Negishi K, Kato S (1983) Dopamine modulates S-poten- 
tial amplitude and dye coupling between external horizontal cells in carp retina. Nature 301:243-246.

Tornqvist K, Yang X-L, Dowling JE (1988) Modulation of cone horizontal cell activity in the teleost fish retina. III. Effects of prolonged darkness and dopamine on electrical coupling between horizontal cells. J Neurosci 8:2279-2288.

Vaney DI (1991) Many diverse types of retinal neurons show tracer coupling when injected with biocytin or neurobiotin. Neurosci Lett 125:187-190.

van Swigchem H (1981) Electrotonic coupling within a cluster of neurosecretory endogenous oscillators in Lymnaea stagnalis (L.). Comp Biochem Physiol [A] 68:199-209.

Voorn P, Docter GJ (1992) A rostrocaudal gradient in the synthesis of enkephalin in nucleus accumbens. Neuroreport 3:161-164.

Walsh JP, Cepeda C, Hull CD, Fisher RS, Levine ML, Buchwald NA (1989) Dye coupling in the neostriatum of the rat: II. Decreased coupling between neurons during development. Synapse 4:238-247.

Walton KD, Navarrete R (1991) Postnatal changes in motoneurone electrotonic coupling studied in the in vitro rat lumbar spinal cord. $\mathrm{J}$ Physiol (Lond) 433:283-305.

White FJ, Wang RY (1983) Differential effects of classical and atypical antipsychotic drugs on $A 9$ and A10 dopamine neurons. Science 221: $1054-1057$.

Williams JEG, Woolverton WL (1990) The D2 agonist quinpirole potentiates the discriminative stimulus effects of the D1 agonist SKF 38393. Pharmacol Biochem Behav 37:289-293.

Wyatt RJ, Alexander RC, Egan MF, Kirch DG (1988) Schizophrenia, just the facts. What do we know, how well do we know it? Schizophrenia Res 1:3-18.

Wylie RM (1973) Evidence of electrotonic transmission in the vestibular nuclei of the rat. Brain Res 50:179-183.
Yamada $\mathrm{E}$, Ishikawa $\mathrm{T}$ (1965) The fine structure of the horizontal cells in some vertebrate retinae. Cold Spring Harbor Symp Quant Biol 30:383-392.

Záborszky L, Alheid GF, Beinfeld ML, Eiden LF, Heimer L, Palkovits M (1985) Cholecystokinin innervation of the ventral striatum: a morphological and radioimmunological study. Neuroscience 14:427453.

Zahm DS (1992) An electron microscopic morphometric comparison of tyrosine hydroxylase immunoreactive innervation in the neostriatum and the nucleus accumbens core and shell. Brain Res 575:341346.

Zahm DS, Brog JS (1992) On the significance of subterritories in the "accumbens" part of the rat ventral striatum. Neuroscience 50:751767.

Zahm DS, Heimer L (1988) Ventral striatopallidal parts of the basal ganglia in the rat: I. Neurochemical compartmentation as reflected by the distributions of neurotensin and substance $P$ immunoreactivity. J Comp Neurol 272:516-535.

Zahm DS, Heimer L (1990) Two transpallidal pathways originating in the rat nucleus accumbens. J Comp Neurol 302:437-446.

Zahm DS, Heimer L (1992) Specificity in the efferent projections of the nucleus accumbens in the rat: comparison of the rostral pole projection patterns with those of the core and shell. Soc Neurosci Abstr 18:308.

Zoli M, Cintra A, Zini I, Hersh LB, Gustafsson J-A, Fuxe K, Agnati LF (1990) Nerve cell clusters in dorsal striatum and nucleus accumbens of the male rat demonstrated by glucocorticoid receptor immunoreactivity. J Chem Neuroanat 3:355-366. 